\title{
A Contractual Analysis of State versus Private Ownership ${ }^{1}$
}

\author{
Kun Jiang ${ }^{2}$ and Susheng Wang3
}

January 2017

\begin{abstract}
We uniquely analyze the advantages and disadvantages of private ownership versus state ownership under various circumstances by focusing on three aspects: external risk, internal governance, and relative importance of owners versus managers. Our theoretical analysis indicates that private ownership is better than state ownership if the business environment is risky, corruption is limited, or the manager plays a more important role than the owner. Our empirical analysis supports our theoretical findings and reveals that better internal governance, more external risk and greater importance of the manager will magnify the benefits of privatization.
\end{abstract}

Keywords: contractual analysis, state ownership, private ownership, incentives, external risks, internal corruption.

JEL Classification: D23, D73, P31

${ }^{1}$ We gratefully acknowledge the helpful comments and suggestions from two referees and the funding support from the Research Grants Council and the Central Policy Unit of the Hong Kong SAR Government.

2 Roehampton University, UK. Email: Kun.Jiang@roehampton.ac.uk.

3 Hong Kong University of Science and Technology. Email: s.wang@ust.hk. 


\section{Introduction}

The transformation of state-owned enterprises (SOEs) to private firms has been among the most important economic events in recent times. SOEs are generally considered as inefficient and in the past 20 years, privatization has been the approach to their reform in more than 100 countries, including many Western countries such as the U.K., France and Canada, as well as Eastern Bloc countries and China. Privatization transforms a state-owned company to a privately owned one. A key outcome of this process is that the nature of the contractual relationships between owners and managers changes following the change in ownership. The main problem with SOEs is incentive and the contractual approach has been recognized as the main mechanism addressing this problem.

This paper focuses on contractual relationships. We analyze the advantages and disadvantages of private ownership versus state ownership under various circumstances within the same model setting. We shed light on privatization from a unique angle by focusing on three aspects: external risks, internal governance, and the relative importance of owners versus managers. We also present empirical evidence in support of our theoretical findings.

The contractual relationships we focus on are based on the ownership structure of a company. One key characteristic of private ownership is profit maximization, as opposed to social welfare maximization. One key characteristic of state ownership is the political doctrine of equal pay for all. However, over the years, the system of equal pay has suffered from severe incentive problems. Consequently, this system was adjusted to allow for bonuses, which implies a conditional fixed contract. A conditional fixed contract offers a fixed pay with a bonus, where the bonus is conditional on a performance target. We impose two key assumptions in our model. Under private ownership, (a) the firm is privately owned and the owner maximizes profits and (b) any contract is admissible. In contrast, under state ownership, (a) the firm is state-owned and the owner maximizes social welfare and (b) only conditional fixed contracts are admissible. The firm faces the same conditions in either ownership arrangement, including the same incentive problems, external risks and internal corruption. It turns out that neither ownership arrangement completely dominates the other in terms of economic efficiency. The question is which arrangement is better under what conditions.

We make the following theoretical findings. First, if the business environment is fairly risky, the market solution is always better than the planning solution. Second, if the role of the manager is important, the market solution is better. Third, if corruption can be effectively controlled, the market solution is better. Finally, if a safer environment is coupled with more effective control of corruption, the market solution is better. These results are new to the literature. 
One key advantage of the planning solution is that the planner's objective is aligned with the efficiency criterion (social welfare maximization); but one key disadvantage is that the planning solution offers weak incentives to economic agents. On the other hand, one key advantage of the market solution is that it offers strong incentives to economic agents; but one key disadvantage of the market solution is that private firms' objective (profit maximization) is not aligned with the efficiency criterion. Economic agents are much more willing to work hard in good times. Hence, if a good time is very likely, the advantage in objective alignment overweighs the disadvantage in weak incentives so that the planning solution is better than the market solution. However, under normal circumstances as described in our findings, the market solution is better.

Using a database containing 1,046 listed firms in the Chinese stock markets, including Chinese SOEs, privately owned firms and foreign firms, we empirically investigate the change in firm value before and after the announcement of privatization. We compare the same companies before and after the announcement of privatization across time; we also compare different companies under different forms of ownership at a given time. In our regression model, we include the three key factors in our theoretical model (internal governance, external risks, and the relative importance of the owner) as independent variables. We make the following empirical findings. First, we find that the three factors are significantly associated with firm value and these associations are consistent with our theoretical predictions. Specifically, firm value increases with the strength of internal governance and the relative importance of the manager, and decreases with the degree of external risks. Second, the magnitude of the increase in firm value after the announcement of privatization is determined by the three factors as well. Specifically, better internal governance, greater external risk or higher importance of the manager will magnify the benefits of privatization. To our knowledge, these findings are new to the literature.

Privatization has become a hot topic in the literature. Researchers have looked at various aspects of privatization (see the surveys by Megginson \& Netter (2001), Bonin \& Wachtel (2003) and Turhan (2005)). Most studies claim that SOEs are inefficient and try to find reasons for the inefficiency. Ehrlich et al. (1994) show that private ownership leads to higher productivity growth in the long run, but that the ownership effect is ambiguous in the shortrun. Bai et al. (2000) stress the role of SOEs in providing social safety, which reduces profitability. Sun \& Tong (2003) find that privatization is effective in improving SOEs' earnings ability, real sales, and workers' productivity, but fails to boost profit returns and leverage. Gupta (2005) finds that partial privatization has a positive impact on profitability, productivity, and investment in Indian SOEs. Bai \& Xu (2005) consider multiple tasks of SOEs and try to disentangle the complementarity from the substitutability of incentives. D'Souza et al. (2005) show that ownership (both private and foreign), the degree of economic freedom, and the level of capital market development significantly affect post-privatization performance. Boubakri et 
al. (2005a) find that the relinquishment of control by the government is a key determinant of profitability, efficiency gains and output increases. Recently, Jiang \& Wang (2012) analyze a market-oriented, multistage privatization process and show that the lockup effect, demand elasticity, growth potential and business fluctuations can all affect staged privatization.

On the contrary, some studies have suggested that state ownership is not necessarily less efficient than private ownership. Caves \& Christensen (1980) study two major Canadian railroads under different ownership structures; they do not find state ownership to be less efficient than private ownership. Vernon-Wortzel \& Wortzel (1989) suggest that SOEs perform better than private enterprises. Martin \& Parker (1995) examine 11 U.K. firms that were privatized in the 1980s; they do not find evidence that private ownership is unequivocally more efficient than nationalization. Chang \& Singh (1997) argue that SOEs and large private firms both face the same unwieldy bureaucracies. Since private firms have no inherent advantages in corporate governance, there is no guarantee that they are more efficient than SOEs. Kole \& Mulherin (1997) study a sample of US companies; they find that the SOEs did not deliver a significantly different performance than private firms in the same industry. In a cost-benefit analysis, Schmitz (2000) identifies conditions under which private ownership, state ownership or partial ownership is optimal. Finally, Aussenegg \& Jelic (2006) examine the operating performance of companies privatized in three central European transition economies between 1990 and 1998. They find that, in the first six years after privatization, the firms experienced a drop in profitability, capital investments, employment, and output as well as a significant increase in leverage. Their results indicate the importance of an appropriate legal and institutional environment for the performance of newly privatized firms in transition economies.

The existing theoretical studies on privatization typically attribute the inefficiency of SOEs to a government that does not maximize social welfare or the failure of the political system. ${ }^{4}$ For example, Perotti (1995) assumes that the government maximizes its revenue and partial privatization serves as a signal from the government. Bai et al. (2000) and Bai \& Xu (2005) propose a multitask agency theory for the inefficiency of SOEs. Bai et al. (2000) assume that SOEs are always less efficient than private firms, whereas Bai \& Xu (2005) assume that the government maximizes its revenue and they restrict admissible contracts to linear contracts only. In contrast, we provide an ownership-based contractual theory with a government that maximizes social welfare. We use a general social welfare function, allowing for various weights of social welfare on firm value and the manager's payoff.

Our model is unique. Instead of arguing that one form of ownership is always better than the other, we show that each can dominate under the right circumstances. We also provide empirical evidence supporting our theoretical predictions. Our theory suggests that a gradual

4 E.g., Jones (1985), Sappington \& Stiglitz (1987), Vickers \& Yarrow (1988), Shleifer \& Vishny (1994), Perotti (1995), and Shleifer (1998). 
reform process may be better than a one-time reform. As the business environment evolves over time, state ownership is gradually replaced by private ownership in the context of reform.

This paper is organized as follows. Section 2 introduces our theoretical model. Section 3 presents the contractual relationship between the owner and the manager in a market economy. Section 4 presents the contractual relationship between the owner and the manager under central planning. Section 5 analyses and compares the two contractual relationships. We find conditions under which the market solution is better than the planning solution, and vice versa. Section 6 presents an empirical study and the results. Finally, Section 7 concludes this paper with a summary and remarks. All the proofs are given in the Appendix.

\section{The Model}

Consider a company that may be state or privately owned. We investigate the contractual relationships between the owner and the manager in the two ownership environments. The relationships are defined by a principal-agent model, in which the owner is the principal and the manager is the agent.

Besides ownership, risks in the business environment (external risk) and integrity of internal governance (corruption/stealing) are two important aspects in the relationships. We use output uncertainty to represent external risk. Specifically, let output be

$$
\tilde{x}=f(a, b)+\tilde{\varepsilon},
$$

where $a \geq 0$ is the manager's action/effort, $b \geq 0$ is the owner's action/effort, $\tilde{\varepsilon}$ is a random shock with mean $\bar{\varepsilon} \equiv E(\tilde{\varepsilon})$, and $f: \mathbb{R}_{+}^{2} \rightarrow \mathbb{R}$ is the production function. The random shock $\tilde{\varepsilon}$ and actions $a$ and $b$ are not contractable/verifiable. Let $c(a)$ and $C(b)$ be the private costs of actions $a$ and $b$, respectively, where "private costs" means that they are not contractable. The actual output $\tilde{x}$ is known to the manager only when it is produced; hence, it is also not contractable. In fact, only the reported output, which is defined below, is contractable in our model.

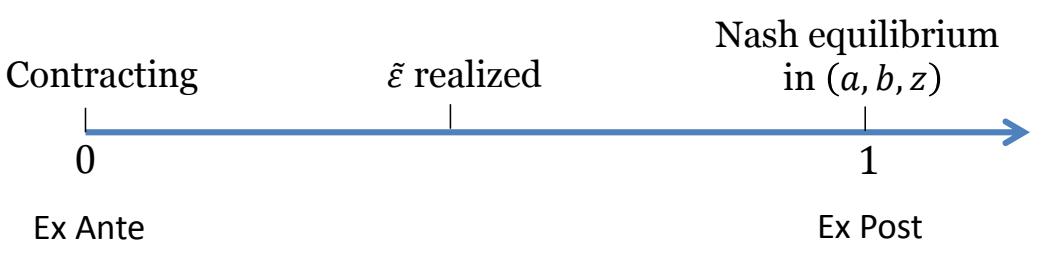

Figure 1. Timeline of Events

As indicated in the above timeline, at the time of contracting, the random shock is not yet realized; but at the time when the manager and the owner take their actions, the random shock is realized and publicly known. Specifically, at the time when the owner offers a contract to the manager, both parties know the distribution function $\Psi$ of $\tilde{\varepsilon}$ but not $\tilde{\varepsilon}$, where $\Psi$ is inde- 
pendent of the action variables; and at the time when they take actions, they know the value of $\tilde{\varepsilon}$. This reflects the fact that, under central planning, contracts are typically decided in advance in a 5-year plan, but actions are taken throughout the 5-year period. Even in a market economy, evidence suggests that contractual relationships are stable over time. 5

Internal corruption is another important aspect. The manager possesses certain control rights, which she may exercise to her own benefits. The extent of corruption is measured by how much of the company's output the manager steals. To prevent corruption, a monitoring system is set up to catch theft with a certain probability. Specifically, let $z$ be the amount of stealing by the manager, $p$ be the probability of catching the manager stealing, and $\phi(z)$ be the monetary penalty if the manager is caught stealing. The stolen amount $z$ is unobservable and hence not contractable. After stealing the amount $z$, the manager announces output $\tilde{x}-z$. This reported output is contractable. A contract is a function $s: \mathbb{R} \rightarrow \mathbb{R}$ that specifies payment $s(\tilde{x}-z)$ to the manager.

Payoff is defined as income minus cost. In particular, the owner's payoff is the firm's profit minus his cost of action, and the manager's payoff is the manager's income minus her cost of action. Although both the owner and the manager are risk neutral in income, they are risk averse in payoff since their cost functions are convex. Under private ownership, the owner maximizes his expected payoff $V$. Under state ownership, the owner is the government, which maximizes social welfare, where social welfare is defined by

$$
W=V+\delta U,
$$

where $U$ is the manager's expected payoff, and $\delta \geq 0$ is an arbitrary fixed number that serves as the weight of social welfare on the manager's payoff. When $\delta=0$, the government cares about the firm's payoff only.

As indicated by the timeline, our solution is a subgame perfect Nash equilibrium. The principal offers a take-it-or-leave-it contract ex ante, conditional on an ex post Nash equilibrium in actions. After the contract is accepted, the two parties take actions ex post and reach a Nash equilibrium in the ex post subgame.

We impose standard assumptions on the functions:

$$
\begin{aligned}
& \phi^{\prime}(z) \geq 0, \quad \phi^{\prime \prime}(z) \geq 0, \\
& c^{\prime}(a) \geq 0, \quad c^{\prime \prime}(a) \geq 0, \quad C^{\prime}(b) \geq 0, \quad C^{\prime \prime}(b) \geq 0, \\
& f_{a}(a, b) \geq 0, \quad f_{b}(a, b) \geq 0, \quad f_{a a}(a, b) \leq 0, \quad f_{b b}(a, b) \leq 0,
\end{aligned}
$$

Further, assume that $\phi(0)=c(0)=C(0)=0$.

5 A recent paper by Chen et al. (2015) investigates organizational structures and contractual terms in franchise chains in the US, taking into account spatial factors such as the intensity of competition, industry types and physical distances. Their results suggest that contractual terms may be more stable than organizational structures among competing firms. 


\section{The Market Solution}

In the market economy,

(a) the firm is privately owned and the owner maximizes profits;

(b) any contract is admissible.

Specifically, the set of admissible contracts is

$$
\mathcal{S}=\{s: \mathbb{R} \rightarrow \mathbb{R} \mid s \text { is Lebesgue integrable }\} .
$$

Suppose that the firm is owned by a private owner who cares about profit. This owner offers an admissible contract to the manager. After accepting the contract, with a realized value of $\tilde{\varepsilon}$, in the ex post subgame of actions, given the owner's action $b$ in Nash equilibrium, the manager's problem is:

$$
\max _{a, z} s[f(a, b)+\tilde{\varepsilon}-z]-c(a)+(1-p) z-p \phi(z),
$$

where $(1-p) z$ is the manager's expected income from stealing and $p \phi(z)$ is the expected penalty for stealing. Problem (3) implies two first-order conditions (FOCs):

$$
\begin{aligned}
& s^{\prime}[f(a, b)+\tilde{\varepsilon}-z] f_{a}(a, b)=c^{\prime}(a), \\
& 1-p=s^{\prime}[f(a, b)+\tilde{\varepsilon}-z]+p \phi^{\prime}(z) .
\end{aligned}
$$

These FOCs are called incentive comparability (IC) conditions. These two equations imply $\hat{a}(\varepsilon, b)$ and $\hat{z}(\varepsilon, b)$. We will also consider the second-order conditions (SOCs). On the other hand, after the contract is accepted and given the manager's actions $(a, z)$ in Nash equilibrium, the owner's problem is

$$
\max _{b} f(a, b)+\tilde{\varepsilon}-s[f(a, b)+\tilde{\varepsilon}-z]-(1-p) z+p \phi(z)-C(b) .
$$

This implies an FOC:

$$
f_{b}(a, b)\left\{1-s^{\prime}[f(a, b)+\tilde{\varepsilon}-z]\right\}=C^{\prime}(b) .
$$

This is a third IC condition, and it implies $\hat{b}(\varepsilon, a, z)$. We will also consider the SOC. The three IC conditions jointly determine an ex post Nash equilibrium in actions. Then, the owner's exante contractual problem is

$$
\begin{aligned}
V^{*}=\max _{a, b, z, s(\cdot)} & E\{f(a, b)+\tilde{\varepsilon}-s[f(a, b)+\tilde{\varepsilon}-z]-(1-p) z+p \phi(z)\}-C(b) \\
\text { s.t. } & I C_{1}: s^{\prime}[f(a, b)+\tilde{\varepsilon}-z] f_{a}(a, b)=c^{\prime}(a), \\
& I C_{2}: f_{b}(a, b)\left\{1-s^{\prime}[f(a, b)+\tilde{\varepsilon}-z]\right\}=C^{\prime}(b), \\
& I C_{3}: 1-p=s^{\prime}[f(a, b)+\tilde{\varepsilon}-z]+p \phi^{\prime}(z), \\
& S O C s: \text { Two SOCs for }(3) \text { and one SOC for }(4), \\
& I R: E\{s[f(a, b)+\tilde{\varepsilon}-z]-c(a)+(1-p) z-p \phi(z)\} \geq 0 .
\end{aligned}
$$

The last condition is the individual-rationality (IR) condition for the manager, stating that the manager's expected payoff is positive. Note that $a, b$, and $z$ are functions of $\varepsilon$. The solution to problem (5) is stated in the following proposition. 
Proposition 1 (Market Solution). Suppose the following problem has a solution $\left(a^{*}, b^{*}\right)$.

$$
\begin{gathered}
V^{*}=\max _{a, b \geq 0} f(a, b)-c(a)-C(b)+\bar{\varepsilon} \\
\text { s.t. } \frac{c^{\prime}(a)}{f_{a}(a, b)}+\frac{C^{\prime}(b)}{f_{b}(a, b)}=1 .
\end{gathered}
$$

Given this $\left(a^{*}, b^{*}\right)$, let $z^{*}$ be a solution to the following equation:

$$
\frac{c^{\prime}\left(a^{*}\right)}{f_{a}\left(a^{*}, b^{*}\right)}+p\left[1+\phi^{\prime}(z)\right]=1 .
$$

Then an optimal solution under the market economy exists and it is $\left(a^{*}, b^{*}, z^{*}, s^{*}(\cdot)\right)$, where $s^{*}(\cdot)$ is a linear contract $s^{*}(x)=\alpha^{*}+\theta^{*} x$ with $\alpha^{*}$ and $\theta^{*}$ being constants defined by

$$
\begin{aligned}
\theta^{*} & =\frac{c^{\prime}\left(a^{*}\right)}{f_{a}\left(a^{*}, b^{*}\right)} \\
\alpha^{*} & =c\left(a^{*}\right)-(1-p) z^{*}+p \phi\left(z^{*}\right)-\theta^{*}\left[f\left(a^{*}, b^{*}\right)+\bar{\varepsilon}-z^{*}\right] .
\end{aligned}
$$

We have $\theta^{*} \in(0,1)$.

Notice that this solution under the market economy is independent of the random shock $\tilde{\varepsilon}$ except for its mean $\bar{\varepsilon}$. However, the solution under central planning will be dependent on the random shock and this dependence is crucial.

\section{The Planning Solution}

Under central planning,

(a) the firm is state-owned and the owner maximizes social welfare;

(b) only conditional fixed contracts are admissible.

Because of the political doctrine which emphasizes equal pay for all, contracts in SOEs have the following form:

$$
s(x)= \begin{cases}s_{l} & \text { if } x<x_{0} \\ s_{h} & \text { if } x \geq x_{0}\end{cases}
$$

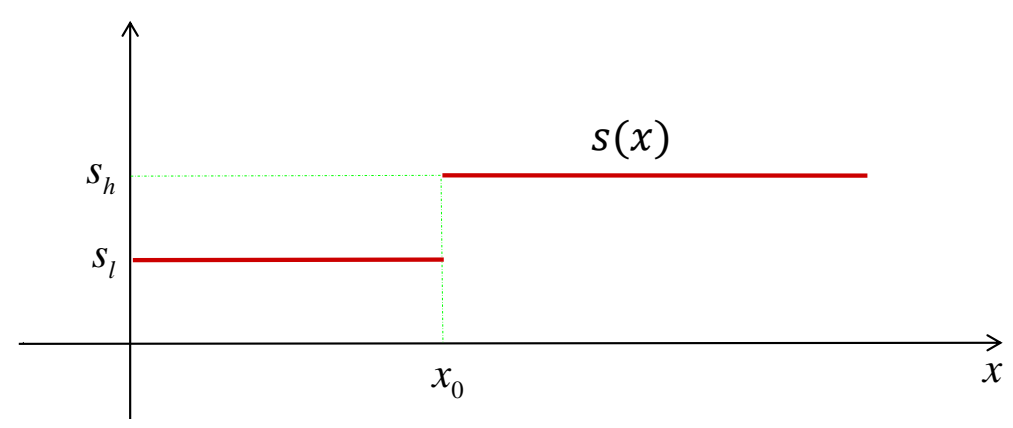

Figure 2. A Conditional Fixed Contract 
We call this form of contract a conditional fixed contract. Admissible contracts under state ownership are conditional fixed contracts. The political doctrine means that the pay is independent of performance. However, over the years, this system of equal pay has suffered from severe incentive problems. Consequently, this system was adjusted to allow for bonuses, which leads to the above conditional fixed contract with a conditional bonus $s_{h}-s_{l} \cdot{ }^{6}$ Although this contract may seem less efficient than a more flexible contract, as shown in our solution, it can be more efficient than the optimal contract in the market economy under some circumstances.

Under central planning, a contract is typically formulated in advance under a 5-year plan. By the time the contract is implemented, the economic situation may have changed dramatically. If the performance target $x_{0}$ is set too low, the manager may not give her best, especially when the economic situation is good; if $x_{0}$ is set too high, the manager may give up altogether trying to meet this target, especially when the economic situation is bad. Hence, if the output is fairly uncertain, such a contract may be quite inefficient and could lead to serious corruption.

In contrast to the optimal solution in the market economy, the optimal solution under central planning is heavily dependent on the state of the economic environment. To facilitate discussion, we assume that $\tilde{\varepsilon}$ takes only two possible values: $\varepsilon_{g}$ in good times with probability $q$, and $\varepsilon_{b}$ in bad times with probability $1-q$, where $\varepsilon_{g}>\varepsilon_{b}$, i.e.,

$$
q \equiv \operatorname{Pr}\left(\tilde{\varepsilon}=\varepsilon_{g}\right), \quad 1-q \equiv \operatorname{Pr}\left(\tilde{\varepsilon}=\varepsilon_{b}\right) .
$$

Correspondingly, each action variable is associated with two possible actions: the action in good times and the action in bad times. In good times, the manager may or may not act to obtain the high pay $s_{h}$; in bad times, the manager may or may not act to obtain the low pay $s_{l}$. Hence, there are four possible combinations of actions and economic situations. We use the following subscripts to distinguish the actions and economic situations:

$$
g=\text { good times, } \quad b=\text { bad times }, \quad h=\text { high pay, } \quad l=\text { low pay. }
$$

After accepting the contract, with a realized value $\varepsilon_{i}$, in the ex post subgame, given the owner's action $b$ in Nash equilibrium, the manager's problem is

${ }^{6}$ This bonus can be in the form of a promotion. Under central planning, wages are based on a ladder system. The wage for each ladder is fixed. An employee can be promoted to a higher wage ladder under certain conditions, but he/she typically stays at the same wage ladder for many years. For example, Groves et al. (1995) mention that, under central planning, "Contracts generally had 3- or 4-year terms" and "The contracts committed the manager to meet certain performance indicators and established a structure of rewards and penalties. Profitability was always one of the performance indicators and was listed as the most important indicator." Bai \& Xu (2005) also mention that "A contract specified performance targets" and "Wages of employers and managers were determined according to a deterministic formula based on personal characteristic, e.g., age, tenure, education, residence, gender, and job title." 


$$
u \equiv \max _{a, z \geq 0} s\left[f(a, b)+\varepsilon_{i}-z\right]-c(a)+(1-p) z-p \phi(z)
$$

With the conditional fixed contract in (9), the manager's ex post payoff is

$$
u= \begin{cases}s_{l}-c(a)+(1-p) z-p \phi(z) & \text { if } f(a, b)+\varepsilon_{i}-z<x_{0}, \\ s_{h}-c(a)+(1-p) z-p \phi(z) & \text { if } f(a, b)+\varepsilon_{i}-z \geq x_{0} .\end{cases}
$$

Given a value $\varepsilon_{i}$, if the manager is aiming for the low pay $s_{l}$, then by (11) problem (10) implies that her choices $\left(a_{i, l}, z_{i, l}\right)$ must satisfy

$$
a_{i, l}=0, \quad \phi^{\prime}\left(z_{i, l}\right)=\frac{1-p}{p} .
$$

Here, the subscripts $(i, l)$ mean that, when $\tilde{\varepsilon}=\varepsilon_{i}$ the manager is aiming for the low pay $s_{l}$. We can see that the choices are the same whether $i=g$ or $b$.

On the other hand, given a value $\varepsilon_{i}$, if the manager is aiming for the high pay $s_{h}$, then by (11) problem (10) implies that her choices $\left(a_{i, h}, z_{i, h}\right)$ are obtained from the following problem:

$$
\begin{aligned}
\max _{a, z \geq 0} & s_{h}-c(a)+(1-p) z-p \phi(z) \\
\text { s.t. } & f(a, b)+\varepsilon_{i}-z \geq x_{0} .
\end{aligned}
$$

In this case, the manager will try to choose as small an $a$ as possible until the constraint becomes binding. The constraint must therefore be binding, implying that

$$
z_{i, h}=f\left(a_{i, h}, b\right)+\varepsilon_{i}-x_{0},
$$

where the subscripts $(i, h)$ mean that, when $\tilde{\varepsilon}=\varepsilon_{i}$ the manager is aiming for the high pay $s_{h}$. Then, problem (13) can be rewritten as

$$
\max _{a} s_{h}-c(a)+(1-p)\left[f(a, b)+\varepsilon_{i}-x_{0}\right]-p \phi\left[f(a, b)+\varepsilon_{i}-x_{0}\right] .
$$

This problem implies that

$$
\frac{c^{\prime}\left(a_{i, h}\right)}{f_{a}\left(a_{i, h}, b\right)}+p\left[1+\phi^{\prime}\left(z_{i, h}\right)\right]=1 .
$$

Equations (14) and (15) jointly determine $\left(a_{i, h}, z_{i, h}\right)$. Since $1>p\left[1+\phi^{\prime}\left(z_{i, h}\right)\right]$ by (15) and $1=$ $p\left[1+\phi^{\prime}\left(z_{i, l}\right)\right]$ by (12), we know that $z_{i, h}<z_{i, l}$, indicating less corruption when the manager is aiming for the high pay.

Assume that the government cares about social welfare, where the social welfare function is defined in (2). After a contract is accepted and given the manager's actions $\left(a_{i, h}, z_{i, h}\right)$ in Nash equilibrium, the owner-armed with the knowledge of $\varepsilon_{i}$-decides on $b$ as follows:

$$
\begin{aligned}
\max _{b} f\left(a_{i, h}, b\right) & +\varepsilon_{i}-s_{h}-(1-p) z_{i, h}+p \phi\left(z_{i, h}\right)-C(b) \\
& +\delta\left[s_{h}-c\left(a_{i, h}\right)+(1-p) z_{i, h}-p \phi\left(z_{i, h}\right)\right] .
\end{aligned}
$$

Equation (16) implies an IC condition:

$$
f_{b}\left(a_{i, h}, b_{i, h}\right)=C^{\prime}\left(b_{i, h}\right) .
$$


Similarly, given the manager's actions $\left(a_{i, l}, z_{i, l}\right)$ in Nash equilibrium, the IC condition is

$$
f_{b}\left(a_{i, l}, b_{i, l}\right)=C^{\prime}\left(b_{i, l}\right) \text {. }
$$

Then, equations (12) and (18) determine an ex post Nash equilibrium $\left(a_{i, l}, b_{i, l}, z_{i, l}\right)$, and equations (14), (15) and (17) determine another ex post Nash equilibrium $\left(a_{i, h}, b_{i, h}, z_{i, h}\right)$.

Given the two possible Nash equilibria $\left(a_{i, l}, b_{i, l}, z_{i, l}\right)$ and $\left(a_{i, h}, b_{i, h}, z_{i, h}\right)$, the manager decides between $a_{i, l}$ and $a_{i, h}$. For the manager to choose $a_{i, h}$ over $a_{i, l}$ when $\tilde{\varepsilon}=\varepsilon_{i}$, we need the following IC condition:

$$
s_{h}-c\left(a_{i, h}\right)+(1-p) z_{i, h}-p \phi\left(z_{i, h}\right) \geq s_{l}-c\left(a_{i, l}\right)+(1-p) z_{i, l}-p \phi\left(z_{i, l}\right) .
$$

We consider only the situation in which (19) holds when $\tilde{\varepsilon}=\varepsilon_{g}$ and fails when $\tilde{\varepsilon}=\varepsilon_{b}$ (see Remark 1 for other situations). Then, (19) implies the following two IC conditions:

$$
s_{h}-c\left(a_{g, h}\right)+(1-p) z_{g, h}-p \phi\left(z_{g, h}\right) \geq s_{l}-c\left(a_{g, l}\right)+(1-p) z_{g, l}-p \phi\left(z_{g, l}\right),
$$

and

$$
s_{h}-c\left(a_{b, h}\right)+(1-p) z_{b, h}-p \phi\left(z_{b, h}\right)<s_{l}-c\left(a_{b, l}\right)+(1-p) z_{b, l}-p \phi\left(z_{b, l}\right) .
$$

That is, the manager aims for the high pay by taking action $a_{g, h}$ in good times; she aims for the low pay by taking action $a_{b, l}$ in bad times. However, without imposing (21), Lemma 3 shows that the manager will aim for the low pay in bad times in equilibrium. Hence, condition (21) is unnecessary. Further, the manager's IR condition is

$q\left[s_{h}-c\left(a_{g, h}\right)+(1-p) z_{g, h}-p \phi\left(z_{g, h}\right)\right]+(1-q)\left[s_{l}-c\left(a_{b, l}\right)+(1-p) z_{b, l}-p \phi\left(z_{b, l}\right)\right] \geq 0$.

The government's expected social welfare is

$$
\begin{aligned}
W=q\{ & f\left(a_{g, h}, b_{g, h}\right)+\varepsilon_{g}-s_{h}-(1-p) z_{g, h}+p \phi\left(z_{g, h}\right)-C\left(b_{g, h}\right) \\
& \left.+\delta\left[s_{h}-c\left(a_{g, h}\right)+(1-p) z_{g, h}-p \phi\left(z_{g, h}\right)\right]\right\} \\
+ & (1-q)\left\{f\left(a_{b, l}, b_{b, l}\right)+\varepsilon_{b}-s_{l}-(1-p) z_{b, l}+p \phi\left(z_{b, l}\right)-C\left(b_{b, l}\right)\right. \\
& \left.+\delta\left[s_{l}-c\left(a_{b, l}\right)+(1-p) z_{b, l}-p \phi\left(z_{b, l}\right)\right]\right\} .
\end{aligned}
$$

With the above derivation of the equilibria and the IC and IR conditions, the government's exante contractual problem can now be stated:

$$
\begin{aligned}
\widehat{W}=\max _{\substack{a_{g, h}, b_{g, h}, z_{g, h}, a_{b, l}, b_{b, l}, z_{b, l}, S_{l}, s_{h}, x_{0} \geq 0 \\
\text { s.t. }}} & \\
& \frac{f_{b}\left(a_{g, h}, b_{g, h}\right)=C^{\prime}\left(b_{g, h}\right),}{} \\
& \frac{c^{\prime}\left(a_{g, h}\right)}{f_{a}\left(a_{g, h}, b_{g, h}\right)}+p\left[1+\phi^{\prime}\left(z_{g, h}\right)\right]=1, \\
& z_{g, h}=f\left(a_{g, h}, b_{g, h}\right)+\varepsilon_{g}-x_{0}, \\
& a_{b, l}=0, \quad f_{b}\left(0, b_{b, l}\right)=C^{\prime}\left(b_{b, l}\right), \quad \phi^{\prime}\left(z_{b, l}\right)=\frac{1-p}{p}, \\
& \text { IC condition }(20),
\end{aligned}
$$$$
\text { IR condition (22). }
$$ 
The solution to problem (23) is stated in the following proposition.

Proposition 2 (Planning Solution). Assume that $f_{a b}(a, b) \geq 0$ and $\phi$ is increasing and strictly convex with $p\left[1+\phi^{\prime}(0)\right] \leq 1$. Under central planning, an optimal solution exists and is determined through the following steps. First, the manager aims for the high pay in good times and the low pay in bad times as part of her optimal strategy. Second, determine $\left(\hat{a}_{g, h}, \hat{b}_{g, h}, \hat{z}_{g, h}\right)$ from

$$
f_{b}\left(\hat{a}_{g, h}, \hat{b}_{g, h}\right)=C^{\prime}\left(\hat{b}_{g, h}\right), \quad \frac{c^{\prime}\left(\hat{a}_{g, h}\right)}{f_{a}\left(\hat{a}_{g, h}, \hat{b}_{g, h}\right)}+p\left[1+\phi^{\prime}(0)\right]=1, \quad \hat{z}_{g, h}=0 ;
$$

and $\left(\hat{a}_{b, l}, \hat{b}_{b, l}, \hat{z}_{b, l}\right)$ from

$$
\hat{a}_{b, l}=0, \quad f_{b}\left(0, \hat{b}_{b, l}\right)=C^{\prime}\left(\hat{b}_{b, l}\right), \quad \phi^{\prime}\left(\hat{z}_{b, l}\right)=\frac{1-p}{p},
$$

Third, define the optimal conditional fixed contract $\left(\hat{x}_{0}, \hat{s}_{h}, \hat{s}_{l}\right)$ by

$$
\begin{aligned}
& \hat{x}_{0}=f\left(\hat{a}_{g, h}, \hat{b}_{g, h}\right)+\varepsilon_{g}, \\
& \hat{s}_{h}-\hat{s}_{l} \geq(1-p) \hat{z}_{b, l}-p \phi\left(\hat{z}_{b, l}\right)+c\left(\hat{a}_{g, h}\right), \\
& \bar{s}=q c\left(\hat{a}_{g, h}\right)-(1-q)\left[(1-p) \hat{z}_{b, l}-p \phi\left(\hat{z}_{b, l}\right)\right],
\end{aligned}
$$

where $\bar{s} \equiv q \hat{s}_{h}+(1-q) \hat{s}_{l}$ is the mean pay. Finally, calculate social welfare from

$$
\widehat{W}=q\left[f\left(\hat{a}_{g, h}, \hat{b}_{g, h}\right)-c\left(\hat{a}_{g, h}\right)-C\left(\hat{b}_{g, h}\right)\right]+(1-q)\left[f\left(0, \hat{b}_{b, l}\right)-C\left(\hat{b}_{b, l}\right)\right]+\bar{\varepsilon} .
$$

Condition $f_{a b}(a, b) \geq 0$ means that the two inputs are complementary. Notice that the planning solution in Proposition 2 is completely independent of the weight $\delta$ of social welfare on the manager's payoff. Also, since one of the conditions in (24) is an inequality, the optimal contract is not unique.

Remark 1. The manager may pick one of the other three possible combinations of actions and economic situations: (1) in either economic situation, the manager aims for $s_{h}$; (2) in either economic situation, the manager aims for $s_{l}$; and (3) the manager aims for $s_{h}$ in bad times and $s_{l}$ in good times. Under trivial conditions, these solutions are inferior to that in (20)-(21). This is intuitively understandable.

Remark 2. We can also add a social cost of stealing, say $\varphi(z)$, into our model. However, the results are very much the same.

\section{Theoretical Analysis}

To analyze and compare the two contractual solutions, consider the following simple parametric case: 


$$
f(a, b)=\mu_{1} a+\mu_{2} b, \quad c(a)=\frac{1}{2} a^{2}, \quad C(b)=\frac{1}{2} b^{2}, \quad \phi(z)=\frac{1}{2} z^{2},
$$

where $\mu_{1}, \mu_{2}>0$.

\section{The Market Solution}

By Proposition 1, the market solution is

$$
a^{*}=\frac{\mu_{1}^{3}}{\mu_{1}^{2}+\mu_{2}^{2}}, \quad b^{*}=\frac{\mu_{2}^{3}}{\mu_{1}^{2}+\mu_{2}^{2}}, \quad \theta^{*}=\frac{\mu_{1}^{2}}{\mu_{1}^{2}+\mu_{2}^{2}},
$$

and the stolen amount is

$$
z^{*}= \begin{cases}\frac{1}{p} \frac{\mu_{2}^{2}}{\mu_{1}^{2}+\mu_{2}^{2}}-1 & \text { if } \frac{\mu_{2}^{2}}{\mu_{1}^{2}+\mu_{2}^{2}}>p \\ 0 & \text { otherwise. }\end{cases}
$$

Social welfare is

$$
W^{*}=V^{*}=\frac{\mu_{2}^{2} \mu_{1}^{2}+\mu_{1}^{4}+\mu_{2}^{4}}{2\left(\mu_{1}^{2}+\mu_{2}^{2}\right)}+\bar{\varepsilon}
$$

\section{The Planning Solution}

By Proposition 2, the planning solution is

$$
\hat{a}_{b, l}=0, \quad \hat{a}_{g, h}=(1-p) \mu_{1}, \quad \hat{b}_{b, l}=\hat{b}_{g, h}=\mu_{2}, \quad \hat{z}_{b, l}=\frac{1-p}{p}, \quad \hat{z}_{g, h}=0,
$$

and the contract $\left(\hat{x}_{0}, \hat{s}_{h}, \hat{s}_{l}\right)$ is defined by

$$
\begin{aligned}
& \hat{x}_{0}=(1-p) \mu_{1}^{2}+\mu_{2}^{2}+\varepsilon_{g}, \\
& \hat{s}_{h}-\hat{s}_{l} \geq \frac{(1-p)^{2}\left(1+p \mu_{1}^{2}\right)}{2 p}, \\
& \bar{s}=\frac{(1-p)^{2}\left(q p \mu_{1}^{2}-1+q\right)}{2 p} .
\end{aligned}
$$

Social welfare is

$$
\widehat{W}=\frac{q}{2}\left(1-p^{2}\right) \mu_{1}^{2}+\frac{1}{2} \mu_{2}^{2}+\bar{\varepsilon} .
$$

Several remarks about the solutions are in order. First, the planning solution does not depend on the weight $\delta$ of social welfare on the manager's payoff. That is, the planning solution is the same whether or not the government cares about firm profits only and whether or not the government cares about the manager's welfare. Hence, the "for profits" objective is fully aligned with the "for social welfare" objective in equilibrium. This alignment is a feature of contract theory. It holds for both state and private ownership because the owner can design a contract to allocate income properly. 
Second, by (26) we find that there is no corruption under private ownership if the probability that stealing is caught is large enough or if the manager has a relatively important role to play (large $\mu_{1} / \mu_{2}$ ). However, by (27) the owner's expected payoff is independent of $p$, implying that she has no incentive to crack down on corruption. The reason is that the manager's expected income $(1-p) z-p \phi(z)$ from corruption has been taken into account by the owner in the compensation package to the manager. Only if corruption incurs an extra cost, such as a negative effect on the firm's reputation, will a privately owned firm completely eliminate corruption.

Third, by (28), a state-owned firm is corruption free in good times but not in bad times. That is, corruption will occur in a state-owned firm when the economic situation is bad. Further, since social welfare is decreasing in $p$, the owner has the incentive to reduce $p$; and when $p$ is reduced, corruption increases. This is consistent with the real-life observation that serious corruption tends to occur in state-owned firms.

In sum, private ownership can completely eliminate corruption; but state ownership and corruption go hand in hand in bad times, and there is a tendency for corruption to get out of hand. The explanation is that under private ownership, the owner can utilize the contract to effectively control corruption; under state ownership, in good times the owner can effectively control corruption by giving a bonus $s_{h}-s_{l}$, but in bad times no bonuses would be given.

\section{Market vs. Planning Solutions}

The market solution is better than the planning solution under circumstances described in Proposition 3.

Proposition 3 (Market vs. Planning Solutions). The market solution is better if the environment is risky, corruption is limited, or the manager plays a more important role than the owner. More specifically, the market solution is better if and only if

$$
\frac{\mu_{2}}{\mu_{1}} \leq \sqrt{\frac{1}{q\left(1-p^{2}\right)}-1} .
$$

This condition leads to the following conclusions:

(a) If the environment is quite risky $\left(q \leq \frac{1}{\left(1-p^{2}\right)\left[1+\left(\mu_{2} / \mu_{1}\right)^{2}\right]}\right)$, the market solution is better; otherwise the planning solution is better.

(b) If the role of the manager is important $\left(\frac{\mu_{2}}{\mu_{1}} \leq \sqrt{\frac{1}{q\left(1-p^{2}\right)}-1}\right)$, the market solution is better; otherwise the planning solution is better.

(c) If corruption can be effectively curbed $\left(p \geq \sqrt{1-\frac{1}{q\left[1+\left(\mu_{2} / \mu_{1}\right)^{2}\right]}}\right)$, the market solution is better; otherwise the planning solution is better. 
(d) If a safer environment ( a larger $q$ ) is coupled with more effective control of corruption ( $a$ larger $p$ ), the market solution is better; otherwise the planning solution is better.

The planning solution converges to the first best (defined in the Appendix) when $p \rightarrow 0$ and $q \rightarrow 1$. That is, if times are always good, the planning solution can be efficient.7 However, the market solution is better under normal circumstances as described in Proposition 3.

In the market economy, the flexibility of contract form allows the two parties to share risks properly, while the doctrine of equal pay under central planning hinders proper risk sharing. Hence, when business risk is high, the market economy is better than central planning. This explains part (a) of Proposition 3.

When the manager is the sole contributor to the firm $\left(\mu_{1}=0\right)$, the market solution achieves efficiency, ${ }^{8}$ while the planning solution is inefficient since it does not distribute risks properly (as mentioned before). This explains part (b) of Proposition 3.

Under private ownership, the owner's view is narrow-she cares about profits only. In our current model setting, we do not explicitly include a social cost of corruption (as mentioned in Remark 2), i.e., a transaction cost on stealing. This means that corruption causes only a distortion of the income allocation in the current model. This distortion may substantially reduce the owner's incentive in the market economy. Hence, when good times are likely, the planning solution may be better since it ensures that both parties aim for the high pay. This explains parts (c) and (d) of Proposition 3. These results indicate the importance of sound corporate governance in the market economy. This is particularly relevant to the debate on nationalizing banks in the wake of the subprime mortgage crisis.

In summary, business risk justifies a market solution; if business risk is low, sound corporate governance is necessary to justify a market solution; if corruption cannot be effectively curbed and business risk is not high enough to justify a market solution, central planning is generally better; finally, if business risk is low and corporate governance is poor, the dominance of the manager can still justify a market solution; otherwise central planning is better.

Our conclusion is consistent with some empirical studies claiming that the benefits of privatization are conditional on the environment. For example, in developed countries D'Souza et

7 Caves \& Christensen (1980) do not find government ownership to be less efficient than private ownership. They study two major Canadian railroads under different ownership schemes. In their case, demand for railway services tends to be quite stable, which may fall under our case with $q \approx 1$. The authors even find that, in a good period (1963-1975), the state-owned railway company delivers a higher productivity growth than does the privately owned railway company.

${ }^{8}$ In this case, we have a single moral hazard. With a single moral hazard and risk neutrality in income, the optimal linear contract achieves efficiency (the first best) in the market economy. We can also see this by verifying $W^{*}=W^{* *}$ when $\mu_{1}=0$ for $W^{*}$ and $W^{* *}$ in (27) and (59), respectively. 
al. (2005) find that firm-level factors such as the percentage of state and foreign ownership appear to have the most significant impact on post-privatization performance, while in developing countries Boubakri et al. (2005b) identify institutional factors as significant determinants. In the following section, we conduct an empirical analysis based on our theory.

\section{Empirical Analysis}

In this section, we use Chinese data to test our theory. ${ }^{9}$ The advantages of the Chinese data are: (1) many firms are involved; (2) most of these firms are large and dominant firms in their industries; (3) the dataset is rich, containing all sorts of information; and (4) the privatization date can be treated as exogenous since it is heavily influenced by many unobservable factors (Lu et al., 2008), so there is no concern of endogeneity regarding the privatization date.

\subsection{Data Sources and Definition of Variables}

Privatization of firms listed on the Chinese stock exchanges (the split-share reform) began in May 2005 and was almost completed in 2007. ${ }^{10}$ As shown in Li et al. (2011), by the end of 2007, 1,254 firms out of total 1,315 firms, representing over $97 \%$ of the Chinese A-share stock market capitalization at that time, had completed the privatization process. Our dataset covers the years from 2003 to 2007 and is obtained from three sources. Our financial data come mainly from the CCER (China Center for Economic Research) database, which contains data on companies listed on the Chinese stock exchanges. We collect data on corporate governance mainly from the CSMAR (China Stock Market and Accounting Research) database, which contains data on the corporate governance of firms listed on the Chinese stock exchanges. Also, we hand-collected data from the firms' annual reports.

We exclude 1) banks and financial firms, 2) those listed firms whose IPO dates were in 2002, and 3) those listed firms whose debt ratios (total debt to total assets) exceeded $1{ }^{11}$ This process left us with 1046 firms, or more than 90\% of the firms listed on the Chinese stock exchanges. With this database, we empirically investigate the change in firm value before and after privatization.

9 Because of space constraint, only the most important empirical results are presented.

${ }^{10}$ Beginning in May 2005, the firms underwent privatization in groups, one group a time. Excluding the initial two experimental groups, a total of 65 groups were privatized over time. For a detailed description of this splitshare reform, see Lu et al. (2008), Li et al. (2011) and Liao et al. (2014).

${ }^{11}$ We exclude banks and financial firms since their valuation methods are not comparable to those of nonfinancial firms. We exclude companies whose IPO dates were in 2002 since window dressing tends to occur in the first year after the IPO. 
We now define variables for our regression model: ${ }^{12}$

Controller: a category variable describing the types of ultimate controllers, which takes the value of 0 if the controller is the central or a local government (i.e., the firm is an SOE), the value of 1 if the controller is an individual (i.e., the firm is privately owned), and the value of 2 if the controller is a foreign investor. This variable defines private firm and foreign firm, as shown in Table 3. In our dataset, more than $70 \%$ of the firms are SOEs, less than $1 \%$ of the firms are controlled by foreign investors, and the rest are private firms..$^{13}$

$C R \_5$ : the proportion of shares held by the biggest five shareholders.

Tobin's $Q$, or $Q$ : the ratio of the sum of the equity market value, the book value of longterm debt and net current liabilities to the book value of total assets.

First control: a dummy that takes the value of 1 if there exists an absolute controller holding more than $50 \%$ of the shares, and 0 if there is no such controller.

Independence ratio: the ratio of the number of outside directors to the total number of directors. An outside director is a board member and affiliated with the firm only through directorship.

Reform indicator: a dummy that takes the value of 1 if privatization has taken place in a given year, and 0 otherwise.

Industry $Q$ : the annual average $Q$ for firms in an industry. The industry classification is

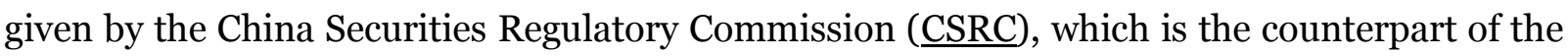

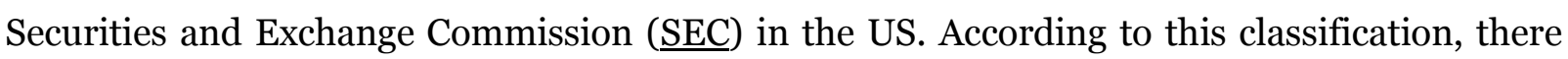
are 13 industries and 76 sub-industries in total in China.

Sales growth rate: the increase in sales over the previous year in percentage.

Leverage: the ratio of debt to total assets.

Depreciation: a yearly accounting expense on the use of assets. The total depreciation is also called accumulated depreciation.

Forced turnover: a dummy that takes the value of 1 if the CEO's contract is terminated prematurely and he/she is forced to depart without there being a more prestigious position waiting for him/her elsewhere, and 0 otherwise.

Institutional shares: the percentage of shares held by institutional investors.

12 We present variables in italics.

${ }_{13}$ All listed firms except four have nontradable shares before 2005. Private firms (privately held firms) also underwent the split-share reform, not just SOEs. We have used a subsample containing only SOEs to run a robustness check. Our main findings remain unchanged using this subsample. That is, the main results remain the same when we focus on SOEs only. 
Liquidity: the average ratio of the daily absolute stock returns to the trading volume in dollars on a given day. It is an illiquidity measure proposed by Amihud (2002).

Asset utilization: the ratio of annual sales to total assets. Note that non-operating income is not included in annual sales in order to avoid the effect of exogenous shocks.

Expense ratio: the ratio of operating expense to annual sales. This definition follows Ang et al. (2000). The operating expense is the total expense less the cost of goods sold, interest expenses, and managerial compensation.

Management share: the proportion of shares held by senior managers, including board members and supervisory committee members.

First mover: a dummy that takes the value of 1 if a firm was privatized in 2005. Year 2005 was the first year of privatization and about 400 firms were privatized in 2005 .

$F C F F$ : the free cash flow of the firm. It equals the operating cash flow minus expenses, taxes, changes in net working capital and changes in investments.

EBITDA: the earnings before interest, taxes, depreciation and amortization.

Big: a dummy variable that takes the value of 1 if the firm is in the top 25 percent in its industry in a given year in terms of size measured by total assets, and 0 otherwise.

HHI: the Herfindahl-Hirschman index, which is a measure of a firm's sales in relation to its industry. We use it as an indicator of a firm's market power.

\subsection{Summary Statistics of Data}

Table 1 reports summary statistics of the key variables, including the number of observations, the mean, the minimum, the maximum, and the standard deviation across the whole sampling period. The variables are winsorized at the 1st and 99th percentiles to eliminate outliers. 


\section{Table 1: Summary Statistics of Listed Firms}

Our sample for 1,046 firms listed on the Chinese stock exchanges during 2003-2007 is obtained from three sources. Our financial data come mainly from the CCER database, which contains data on companies listed on the Chinese stock exchanges. Our data on corporate governance come mainly from the CSMAR database, which contains data on the corporate governance of firms listed on the Chinese stock exchanges. Also, we hand-collected data from the firms' annual reports. The variables are defined in Subsection 6.1. In particular, EBITDA is the earnings before interest, taxes, depreciation and amortization; and $C R \_5$ is the proportion of shares held by the biggest five shareholders.

\begin{tabular}{|c|c|c|c|c|c|}
\hline Variable & Obs & Mean & Std. Dev. & Min & Max \\
\hline Sales (billions) & 5504 & 3.250 & 26.800 & -0.003 & 1200.000 \\
\hline EBITDA (billions) & 5385 & 0.391 & 2.950 & -3.300 & 133.000 \\
\hline ROA & 5534 & 0.984 & 96.084 & -77.482 & 20.920 \\
\hline ROE & 5038 & 5.133 & 95.476 & -113.600 & 44.140 \\
\hline Capital expenditure & 5523 & 0.226 & 2.307 & -1.000 & 100.919 \\
\hline Total assets (billions) & 5543 & 3.810 & 18.000 & 0.000 & 719.000 \\
\hline Depreciation (billions) & 5386 & 0.140 & 1.020 & -0.006 & 43.400 \\
\hline Total depreciation (billions) & 5497 & 0.136 & 1.090 & -0.011 & 42.100 \\
\hline Leverage & 5208 & 0.514 & 0.186 & 0.000 & 0.999 \\
\hline Equity value (billions) & 5634 & 4.090 & 19.900 & -2.040 & 1150.000 \\
\hline Tobin's Q & 5502 & 3.640 & 46.468 & 0.348 & 3164.038 \\
\hline Industry Q & 5560 & 3.652 & 9.651 & 1.188 & 152.023 \\
\hline Liquidity & 5335 & 0.006 & 0.020 & 0.000 & 1.057 \\
\hline Log firm age & 5625 & 2.336 & 0.376 & 1.099 & 3.892 \\
\hline No. of employees (thousands) & 5521 & 3.588 & 12.104 & 0.000 & 400.513 \\
\hline Board & 5441 & 9.634 & 2.209 & 0.000 & 23.000 \\
\hline Independence board & 5441 & 3.245 & 0.874 & 0.000 & 10.000 \\
\hline Independence ratio & 5440 & 0.340 & 0.065 & 0.000 & 0.750 \\
\hline CR_5 & 5430 & 0.545 & 0.146 & 0.023 & 0.960 \\
\hline Shares held by the largest shareholder & 5430 & 0.390 & 0.166 & 0.006 & 0.850 \\
\hline Share held by institutions & 4911 & 0.118 & 0.169 & 0.000 & 0.724 \\
\hline Non-tradable share ratio & 4376 & 0.565 & 0.133 & 0.000 & 0.913 \\
\hline
\end{tabular}

We are interested in the change in firm value before and after privatization. We use a univariate test to examine the changes in the means and medians of Tobin's Q and some operating criteria. We divide our panel data into two groups: those observations before privatization, and those after privatization. The univariate comparison is presented in Table 2. First, we use a binomial test to assess the changes in the means. For each measure, we calculate firmspecific mean values in the years before and after privatization and then test for differences in mean values using a t-statistic. The results show that Tobin's Q, ROA (return on assets), ROE (return on equity), asset utilization and liquidity ${ }^{14}$ all increase significantly. Second, we use a Wilcoxon test to determine the changes in the medians. We use the two-tailed Wilcoxon rank-

${ }_{14}^{14}$ Liquidity is estimated using a measure proposed by Amihud in 2002. The smaller the measure is, the more liquid the stock. 
sum test and the Wilcoxon $\mathrm{Z}$ statistic to check whether the median values in the years before and after privatization have changed significantly (Kazmier \& Pohl, 1984). Table 2 demonstrates that the above results all hold and are not influenced by outliers.

Table 2: Comparison between Firms before and after Privatization

Our sample for 1,046 firms listed on the Chinese stock exchanges during 2003-2007 is obtained from three sources. Our financial data come mainly from the CCER database, which contains data on companies listed on the Chinese stock exchanges. Our data on corporate governance come mainly from the CSMAR database, which contains data on the corporate governance of firms listed on the Chinese stock exchanges. Also, we hand-collected data from the firms' annual reports. The variables are defined in Subsection 6.1. The significance levels at the $1 \%, 5 \%$ and $10 \%$ are identified by ${ }^{* * *},{ }^{* *}$ and ${ }^{*}$, respectively.

\begin{tabular}{|c|c|c|c|c|c|}
\hline & & Before the reform & After the reform & $\mathrm{t}$ value & $\mathrm{z}$ value \\
\hline \multirow[t]{3}{*}{ Tobin's Q } & Mean & 1.924 & 2.221 & $-7.1806 * * *$ & \\
\hline & Median & 1.584 & 1.690 & & $-4.190 * * *$ \\
\hline & Obs & 2889 & 2336 & & \\
\hline \multirow[t]{3}{*}{$\underline{\mathrm{ROA}}$} & Mean & 0.795 & 1.852 & $-8.0845^{* * *}$ & \\
\hline & Median & 2.075 & 3.037 & & $-10.735^{* * *}$ \\
\hline & Obs & 2905 & 2342 & & \\
\hline \multirow[t]{3}{*}{$\underline{\mathrm{ROE}}$} & Mean & 1.541 & 6.252 & $-8.5564 * * *$ & \\
\hline & Median & 4.670 & 6.927 & & $-12.092 * * *$ \\
\hline & Obs & 2687 & 2226 & & \\
\hline \multirow[t]{3}{*}{ Expense ratio } & Mean & 6.497 & 5.683 & $4.0482 * * *$ & \\
\hline & Median & 4.159 & 3.699 & & $4.638^{* * *}$ \\
\hline & Obs & 2825 & 2264 & & \\
\hline \multirow[t]{3}{*}{ Asset utilization } & Mean & 0.618 & 0.706 & $-5.3429 * * *$ & \\
\hline & Median & 0.493 & 0.576 & & $-7.005^{* * *}$ \\
\hline & Obs & 2900 & 2342 & & \\
\hline \multirow[t]{3}{*}{ Liquidity } & Mean & 0.007 & 0.002 & $31.2515^{* * *}$ & \\
\hline & Median & 0.005 & 0.001 & & $39.192 * * *$ \\
\hline & Obs & 2868 & 2280 & & \\
\hline
\end{tabular}

\subsection{Empirical Results}

Tobin's Q describes a firm's investment or growth opportunities. Many scholars, including Daines (2001), Anderson \& Reeb (2003) and Laporta et al. (2002), use it to represent firm value. Following Chung \& Pruitt (1995), we calculate Tobin's Q by dividing the sum of the equity market value, the book value of long-term debt and net current liabilities by the book value of total assets. Chung and Pruitt show that this simplified version of Tobin's $Q$ is not qualitatively different from the complicated version using the replacement value of total assets. Both versions evaluate Tobin's $Q$ at the end of a fiscal year.

The main hypothesis of our empirical study is developed from our theory, which suggests that privatization increases firm value and the magnitude of the increase depends on market 
risk, the strength of corporate governance, and the relative importance of the manager versus the owner. To test this hypothesis, we compare the same companies before and after privatization across time; we also compare different companies under different forms of ownership and business environments at a given time. Since a higher proportion of institutional shares implies better monitoring, we mainly use the proportion of institutional shares to represent the strength of corporate governance (which is the probability $p$ of catching theft in our theory). Our results stay the same if we use non-SOE ownership to represent the strength of corporate governance. Given the fact that higher market power means a more secure firm, we use either the Herfindahl-Hirschman Index ( $\underline{\mathrm{HHI}}$ ) or firm size to represent the probability $q$ of good times. We also use the dummy of whether or not there is a forced turnover to represent the relative importance of the manager $\mu \equiv \mu_{1} / \mu_{2}$. If a new CEO is appointed around the time of privatization, the CEO is more likely to be crucial to the firm.

We find empirical evidence in support of our theoretical findings. First, we find that privatization significantly increases firm value as measured by both Tobin's $Q$ and buy-hold stock returns. Second, our empirical results confirm the theoretical conclusion that the magnitude of the increase in firm value is determined by $p, q$ and $\mu$.

Our empirical analysis is divided into two parts, which are reported in Tables 3, 4 and 5 .

\section{Part 1: The Effect of Privatization on Firm Value (Table 3)}

The purpose of part 1 is to investigate the effect of privatization on firm value. Our basic regression model is as follows:

$$
y_{i j t}=\alpha+\beta_{1} \text { Reform }_{i t}+\beta_{2} y_{j t}+\gamma x_{i j t}+e_{i}+e_{t}+\varepsilon_{i j t}
$$

where $i$ indicates a firm, $j$ indicates an industry, $t$ is time, and $y_{i j t}$ is the dependent variable indicating the market value of firm $i$ in industry $j$ at time $t$ measured by Tobin's Q. Reform fit $_{\text {is }}$ a dummy variable, which equals 1 if the firm went through the reform at time $t$, and 0 otherwise. Another independent variable is $y_{j t}$, which is used to control for the time-variant effect at the industry level measured by the average Tobin's Q of that industry in a given year. A vector of control variables is indicated by $x_{i j t}$. Also, $e_{i}$ controls for time-invariant firm-specific unobserved variables, and $e_{t}$ controls for yearly fixed effects. The effect of the reform is represented by $\beta_{1}$, which is the focus of our attention.

\section{A: No Control Variables}

We first simply regress the firm-level $Q$ on industry $Q$ and reform indicator without controlling for many of the other factors. The industry-average $\mathrm{Q}$ for CSRC-classified industries is included to control for time-varying industry fixed effects, and the controller dummy is used to sort firms into state-owned, private and foreign enterprises. 
We use a fixed effect panel data model to perform regressions, where the heteroscedasticity-consistent standard errors are adjusted within the cluster in all models (Petersen, 2009). Panel (1) of Table 3 shows that the coefficient of the reform indicator is significantly positive. In fact, after privatization, the firm-level Q increases by 0.18 which is approximately $9 \%$ of the mean of the firm-level Q before privatization.

\section{B: Controlling for Financial Factors}

Fama \& French (1998) and Allayannis \& Weston (2001) find evidence of a negative relation between leverage and Q. We thus control for leverage in our regression. As a firm's current and future profitability has an impact on its market value, following Berger \& Ofek (1995) and Yermack (1996), we include ROA and the sales growth rate in our regressions. We use the yearly sales growth rate instead of the yearly earnings growth rate to avoid problems arising from the manipulability of earnings. We also control for FCFF scaled by total sales. According to Jensen (1986), firms with an excess free cash flow are more likely to invest in projects with a negative net present value. Hence, a firm with a low cash flow is expected to have a higher $\mathrm{Q}$. We further control for firm age, industry effect and the type of ultimate controller. We control for firm age because older firms are expected to have better connections with suppliers, customers and the government. As expected, Panel (2) of Table 3 shows that greater leverage implies a smaller Q, while a larger ROA implies a larger Q. However, the effects of FCFF and sales growth are statistically insignificant.

\section{C: Controlling for Corporate Governance}

For Chinese SOEs, privatization is an exogenous event. It allows holders of non-tradable shares (NTS) to sell their shares freely, leading to a change in ownership. Empirical studies have shown that firms with a better ownership structure have a higher market value (Jensen, 1986; Morck et al., 1989; McConnell et al., 1990). We must therefore control for factors related to the ownership structure, such as the proportion of shares held by managers, the proportion of shares held by institutions, the proportion of shares held by the biggest five shareholders, and the first control dummy. ${ }^{15}$

Ownership may be important for managerial incentives. Managers can increase shareholder value in at least two ways. First, they can reduce excess consumption of perquisites. Second, they can invest in riskier assets, implying a transfer of wealth from creditors to shareholders. We therefore control for the proportion of shares held by managers. Theoretical and empirical studies have shown that the larger the proportion of shares held by managers, the higher the firm value.

15 We do not use the proportion of NTS due to serious multicollinearity between this variable and the proportion of shares held by the biggest five shareholders (CR_5). 
We use two indexes to control for ownership concentration: the proportion of shares held by the biggest five shareholders and a dummy indicating whether or not an absolute controller exists. Shleifer \& Vishny (1997) observe that the large premium associated with superior voting shares or control rights is evidence that controlling shareholders seek to extract private benefits from firms, implying a negative effect of ownership concentration on firm value. On the other hand, large shareholders may have incentives to monitor managers closely, implying a positive effect on firm value. Ultimately, the relation between ownership concentration and firm value is an empirical question.

Board composition may also be important for firm value. Yermack (1996) and Eisenberg (1997) find a significant negative correlation between board size and firm value. They explain that, as the number of board members increases, more time is wasted on coordination, implying a negative effect on firm value. We therefore control for board size. We also control for the independence ratio, since outside board members would monitor managers more rigorously.

Last, we also control for whether or not a firm was privatized early (i.e., in 2005). If a firm was privatized early, it would not have had the chance to learn from the experiences of others. That is, those firms that were privatized early would have gained less from privatization.

Panel (3) in Table 3 provides our regression results on ownership structure. It shows that both ownership concentration and management shareholding will increase firm value. Institutional investors increase firm value through their active monitoring. However, the coefficient of the independence ratio is statistically insignificant. With these additional control variables, the coefficient of the reform indicator remains statistically significant.

\section{D: Controlling for Growth Opportunity and Liquidity}

Myers (1977) and Yermack (1996) argue that a firm's investment opportunities can affect its profitability, implying that a firm's future investment opportunities have an impact on its current market value. Following Titman \& Wessels (1988) and Eisenberg (1997), we use each firm's change in assets in the previous year as a proxy for investment opportunities. We also use depreciation in robustness checks. Our regression results demonstrate that the coefficients of the change in assets and depreciation are all significantly positive, indicating a higher firm value for those firms that have better growth opportunities. Also, Panels (4) and (5) of Table 3 show that the coefficients of the reform indicator are still statistically significant even after controlling for future investment opportunities.

\section{Table 3. Effect of Privatization on Firm Value}

Our sample for 1,046 firms listed on the Chinese stock exchanges during 2003-2007 is obtained from three sources Our financial data come mainly from the CCER database, which contains data on companies listed on the Chinese stock exchanges. Our data on corporate governance come mainly from the CSMAR database, which contains data on the corporate governance of firms listed on the Chinese stock exchanges. Also, we hand-collected data from the firms' annual reports. The variables are defined in Subsection 6.1. In particular, Reform indicator is a dummy that takes the value of 1 if privatization has taken place in a given year, and 0 otherwise; $F C F F$ is the free cash flow of the firm, which equals the operating cash flow minus expenses, taxes, changes in net working capital 
and changes in investments; and $C R \_5$ is the proportion of shares held by the biggest five shareholders. The significance levels at the $1 \%, 5 \%$ and $10 \%$ are identified by ${ }^{* * *},{ }^{* *}$ and ${ }^{*}$, respectively.

\begin{tabular}{|c|c|c|c|c|c|}
\hline & (1) & $(2)$ & (3) & (4) & $(5)$ \\
\hline \multirow[t]{2}{*}{ Industry Q } & 0.0120 & -0.000734 & -0.00125 & -0.00164 & -0.00869 \\
\hline & $(0.0122)$ & $(0.00786)$ & $(0.00842)$ & $(0.00836)$ & $(0.00632)$ \\
\hline \multirow[t]{2}{*}{ Reform indicator } & $0.175^{* *}$ & $0.221 * * *$ & $0.220 * * *$ & $0.215^{* * *}$ & $0.206 * * *$ \\
\hline & $(0.0892)$ & $(0.0515)$ & $(0.0509)$ & $(0.0513)$ & $(0.0548)$ \\
\hline \multirow[t]{2}{*}{ Firm age } & & 0.297 & 0.238 & 0.313 & 0.312 \\
\hline & & $(0.267)$ & $(0.293)$ & $(0.277)$ & $(0.269)$ \\
\hline \multirow[t]{2}{*}{ Scaled FCFF } & & 0.000126 & & & \\
\hline & & $(0.0000673)$ & & & \\
\hline \multirow[t]{2}{*}{ Sales growth rate } & & -0.000355 & 0.00000685 & 0.0000581 & 0.000365 \\
\hline & & $(0.000339)$ & $(0.000377)$ & $(0.000362)$ & $(0.000386)$ \\
\hline \multirow[t]{2}{*}{ ROA } & & $0.00882^{*}$ & $0.0123 * *$ & $0.0139 * *$ & $0.00949 * *$ \\
\hline & & $(0.00533)$ & $(0.00588)$ & $(0.00586)$ & $(0.00476)$ \\
\hline \multirow[t]{2}{*}{ Leverage } & & $-1.073 * * *$ & $-1.202 * * *$ & $-1.122 * * *$ & $-1.390 * * *$ \\
\hline & & $(0.298)$ & $(0.341)$ & $(0.333)$ & $(0.279)$ \\
\hline \multirow[t]{2}{*}{ Independence ratio } & & & 0.318 & & \\
\hline & & & $(0.312)$ & & \\
\hline \multirow[t]{2}{*}{ CR_5 } & & & -0.0767 & -0.136 & 0.000522 \\
\hline & & & $(0.285)$ & $(0.288)$ & $(0.288)$ \\
\hline \multirow[t]{2}{*}{ Management share } & & & $11.77 * *$ & & \\
\hline & & & $(5.077)$ & & \\
\hline \multirow[t]{2}{*}{ Institutional share } & & & $0.00568 * * *$ & $0.00560 * * *$ & $0.00612 * * *$ \\
\hline & & & $(0.00156)$ & $(0.00161)$ & $(0.00163)$ \\
\hline \multirow[t]{2}{*}{ Change in fixed assets } & & & & $0.0271 * * *$ & \\
\hline & & & & $(0.00492)$ & \\
\hline \multirow[t]{2}{*}{ Scaled depreciation } & & & & & $3.739 *$ \\
\hline & & & & & $(2.135)$ \\
\hline \multirow[t]{2}{*}{ Liquidity } & & & & & 2.804 \\
\hline & & & & & $(5.709)$ \\
\hline \multirow[t]{2}{*}{ First control } & & & $0.110^{*}$ & $0.110^{*}$ & $0.104 *$ \\
\hline & & & $(0.0565)$ & $(0.0598)$ & $(0.0603)$ \\
\hline \multirow[t]{2}{*}{ First mover } & $-0.332 * * *$ & $-0.285 * * *$ & $-0.284 * * *$ & $-0.296 * * *$ & $-0.267 * * *$ \\
\hline & $(0.0698)$ & $(0.0597)$ & $(0.0530)$ & $(0.0550)$ & $(0.0554)$ \\
\hline \multirow[t]{2}{*}{ Private share } & 0.207 & 0.136 & 0.145 & 0.152 & $0.155^{*}$ \\
\hline & $(0.133)$ & $(0.0994)$ & $(0.0960)$ & $(0.0961)$ & $(0.0930)$ \\
\hline \multirow[t]{2}{*}{ Foreign share } & 0.125 & 0.153 & 0.157 & 0.160 & 0.00810 \\
\hline & $(0.182)$ & $(0.200)$ & $(0.203)$ & $(0.202)$ & $(0.139)$ \\
\hline \multirow[t]{2}{*}{ Constant } & $2.130 * * *$ & $1.969 * * *$ & $2.405 * * *$ & $1.855^{* * *}$ & $1.789 * * *$ \\
\hline & $(0.0499)$ & $(0.552)$ & $(0.760)$ & $(0.607)$ & $(0.620)$ \\
\hline Year effect & $\mathrm{Y}$ & $\mathrm{Y}$ & Y & $\mathrm{Y}$ & $\mathrm{Y}$ \\
\hline Firm fixed effect & Y & Y & Y & Y & $\mathrm{Y}$ \\
\hline $\mathrm{N}$ & 5197 & 5005 & 4531 & 4608 & 4448 \\
\hline adj. R-sq & 0.326 & 0.424 & 0.460 & 0.454 & 0.462 \\
\hline $\mathrm{p}$ & $9.30 \mathrm{e}-185$ & $3.27 \mathrm{e}-230$ & $2.10 \mathrm{e}-217$ & $1.44 \mathrm{e}-213$ & $1.06 \mathrm{e}-208$ \\
\hline
\end{tabular}




\section{Part 2: What Determines the Benefits of Privatization (Tables 4 \& 5)?}

We call the coefficient of the reform indicator the benefits of privatization. Part 1 has shown that privatization brings more benefits to firms than an improved ownership structure and liquidity. The purpose of part 2 is to connect our empirical study and our theory more tightly and determine the factors driving the benefits of privatization. For this purpose, we decompose the coefficient of the reform indicator and demonstrate that its magnitude is determined by the three factors in our theoretical model: the probability $p$ of catching theft, the probability $q$ of good times, and the relative importance $\mu$ of the manager. Our regression model is expanded to incorporate these three factors:

$$
\begin{aligned}
y_{i j t}= & \alpha+\beta_{1} \text { Reform }_{i t}+\beta_{2} y_{j t}+\beta_{31} \text { Riskiness }+\beta_{32} \text { Riskiness } \times \text { Reform }_{i t}+\beta_{41} C G \\
& +\beta_{42} C G \times \text { Reform }_{i t}+\beta_{51} \text { CEO_importance }+\beta_{52} \text { CEO_importance } \times \text { Reform }_{i t} \\
& +\gamma x_{i j t}+e_{i}+e_{t}+\varepsilon_{i j t}
\end{aligned}
$$

To test whether or not the three factors magnify the benefits of privatization, we interact reform indicator with the riskiness of a firm's business environment, corporate governance (CG), and the relative importance of the manager. These three interaction terms enter our regression model. This method is also employed by Lemmon \& Lins (2003), Beck \& Maksimovic (2005), and Kalcheva \& Lins (2007).

Since a higher proportion of institutional shares means more intensive outsider monitoring and less chance for mangers to steal, we mainly use the proportion of institutional shares to represent the strength of corporate governance in our regressions. Based on our theory, we expect this variable to not only have a positive effect on firm value but also magnify the benefits of privatization.

We use either HHI or firm size to represent business riskiness in our regression model (relating to the probability $q$ of good times in our theory). A higher HHI implies a larger market power, thus lower business risk. We also use another dummy called big to represent big firms. It equals 1 if the firm is in the top 25 percent in its industry in a given year in terms of size measured by total assets, and 0 otherwise. Prior literature shows that bigger firms are able to deal with business risk better because of economies of scale, diversification and spillovers. Based on our theory, we expect these variables to have a negative effect on not only firm value but also the benefits of privatization.

Also, we use a dummy on whether there is a forced turnover to measure the relative importance of the manager. Based on our theory, we expect this dummy to have a positive effect on not only firm value but also the benefits of privatization.

The regression results are presented in Tables 4 and 5 . In Table 4 institutional share is a proxy for the probability of catching theft, while in Table 5 the proxy is the Non-SOE dummy. 
In Table 4, we use HHI to measure a firm's market power from Panels (1) to (4), and use big to measure a firm's market power from Panels (5) to (8). From Panels (1) to (8) of Table 4, a firm consistently has a larger Tobin's $Q$ if more of its shares are held by institutional investors, if it has lower market power measured by either HHI or size, or if there is a forced turnover. Moreover, Panels (1) and (5) of Table 4 show that the coefficients of the interaction term between reform indicator and the proportion of institutional shares are significantly positive when only this interaction term is present, implying that sound corporate governance is able to magnify the benefits of privatization. Similarly, Panels (3) and (7) in Table 4 show that the coefficients of the interaction term between reform indicator and forced turnover are significantly positive when only this interaction term is present, indicating the importance of the manager can magnify the benefits of privatization. In Panel (2), HHI is used to measure a firm's market power, and the interaction term between HHI and reform indicator is significantly negative, supporting our theoretical prediction that firms with low business risk benefit less from privatization. The same conclusion is inferred from Panel (6), when we use firm size as a proxy for business risk. Finally, Panels (4) and (8) show that our results above stay the same when the three interaction terms are all present.

The panels also show that even after controlling for the three variables, their interaction terms and the industry effect, the coefficient of the reform indicator is still significantly positive. This means that firm value increases after privatization, confirming once again the results in Table 3.

We have also conducted robustness checks in Table 5 in which the variable institutional share is replaced by the Non-SOE dummy. The Non-SOE dummy is equal to 1 if the listed firm is not an SOE, and 0 otherwise. It is generally believed that a non-SOE's corporate governance is better than that of an SOE, implying that the probability of catching theft is higher in non-SOEs with other things the same. Therefore we use the Non-SOE dummy as a proxy for corporate governance in Table 5 . All of the main findings stay the same, suggesting that the results are robust. Furthermore, in Panels (4) and (8), the coefficients of reform indicator become insignificant once the three interaction terms are included, meaning that the benefits of privatization have been absorbed by the three interaction terms. In other words, the benefits of privatization in our regression model can be fully explained by the three factors in our theoretical model: internal governance, external risk and the relative importance of the manager. Therefore, the three factors fully capture the benefits of privatization, in the sense that privatization does not increase firm value unless the firm has sound corporate governance, operates in a risky business environment, and its manager plays a more important role than the owner. 


\section{Table 4. Determinants of the Benefits of Privatization with Corporate Governance Measured by Institutional Shares}

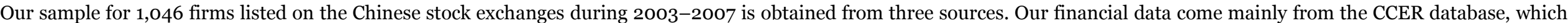

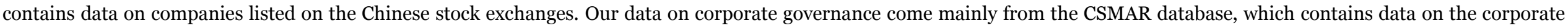

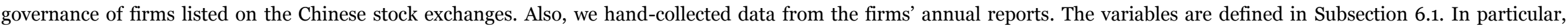

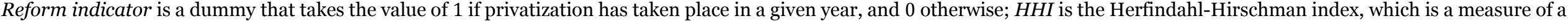

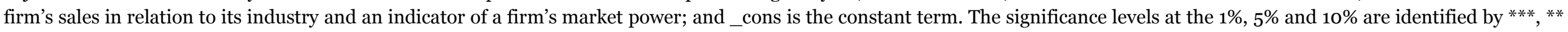
and ${ }^{*}$, respectively.

\begin{tabular}{|c|c|c|c|c|c|c|c|c|}
\hline & (1) & (2) & (3) & (4) & $(5)$ & (6) & (7) & (8) \\
\hline & w_q & w_q & w_q & w_q & w_q & w_q & w_q & w_q \\
\hline \multirow[t]{2}{*}{ Industry Q } & $0.0690 * * *$ & $0.0745^{* * *}$ & $0.0690 * * *$ & $0.0737 * * *$ & $0.0675^{* * *}$ & $0.0678 * * *$ & $0.0674 * * *$ & $0.0668 * * *$ \\
\hline & $(0.00910)$ & $(0.00915)$ & $(0.00902)$ & $(0.00910)$ & $(0.00881)$ & $(0.00857)$ & $(0.00875)$ & $(0.00853)$ \\
\hline \multirow[t]{2}{*}{ Reform indicator } & $0.106 * * *$ & $0.326 * * *$ & $0.173 * * *$ & $0.1375^{* *}$ & $0.0891 * *$ & $0.756^{* * *}$ & $0.152 * * *$ & $0.6296 * * *$ \\
\hline & $(0.0397)$ & $(0.0446)$ & $(0.0360)$ & $(0.0576)$ & $(0.0375)$ & $(0.116)$ & $(0.0344)$ & $(0.1135)$ \\
\hline \multirow[t]{2}{*}{ Institutional share } & $0.00410 * * *$ & $0.0121 * * *$ & $0.0122 * * *$ & $0.00369 * * *$ & $0.00635^{* * *}$ & $0.0146 * * *$ & $0.0142 * * *$ & $0.00407 * * *$ \\
\hline & $(0.00142)$ & $(0.00158)$ & $(0.00158)$ & $(0.00141)$ & $(0.00127)$ & $(0.00148)$ & $(0.00148)$ & $(0.00123)$ \\
\hline \multirow[t]{2}{*}{ Forced turnover } & $0.0974 * * *$ & $0.0955 * * *$ & 0.0302 & 0.0214 & $0.0726^{* *}$ & $0.0873 * * *$ & 0.00288 & 0.0253 \\
\hline & $(0.0330)$ & $(0.0336)$ & $(0.0350)$ & $(0.0348)$ & $(0.0316)$ & $(0.0323)$ & $(0.0344)$ & $(0.0333)$ \\
\hline \multirow[t]{2}{*}{ HHI } & $-0.279 * * *$ & $-0.203^{* * *}$ & $-0.287 * * *$ & $-0.189 * * *$ & & & & \\
\hline & $(0.0457)$ & $(0.0426)$ & $(0.0453)$ & $(0.0431)$ & & & & \\
\hline \multirow[t]{2}{*}{ Big } & & & & & $-1.010 * * *$ & $-0.773 * * *$ & $-1.019 * * *$ & $-0.719 * * *$ \\
\hline & & & & & $(0.0790)$ & $(0.0732)$ & $(0.0786)$ & $(0.0738)$ \\
\hline \multirow[t]{2}{*}{ Reform $\times$ Institutional share } & $0.0115^{* * *}$ & & & $0.0120 * * *$ & $0.0113 * * *$ & & & $0.0154 * * *$ \\
\hline & $(0.00225)$ & & & $(0.00225)$ & $(0.00219)$ & & & $(0.00216)$ \\
\hline \multirow[t]{2}{*}{ Reform $\times \mathrm{HHI}$} & & $-0.208 * * *$ & & $-0.219 * * *$ & & & & \\
\hline & & $(0.0620)$ & & $(0.0616)$ & & & & \\
\hline \multirow[t]{2}{*}{ Reform $\times$ Big } & & & & & & $-0.666 * * *$ & & $-0.784 * * *$ \\
\hline & & & & & & $(0.122)$ & & $(0.122)$ \\
\hline \multirow[t]{2}{*}{ Reform $\times$ Change of CEO } & & & $0.159 * *$ & $0.161 * *$ & & & $0.164^{* *}$ & $0.137 * *$ \\
\hline & & & $(0.0666)$ & $(0.0669)$ & & & $(0.0658)$ & $(0.0625)$ \\
\hline \multirow[t]{2}{*}{ _cons } & $1.677 * * *$ & $1.568 * * *$ & $1.636 * * *$ & $1.655^{* * *}$ & $2.339 * * *$ & $2.073 * * *$ & $2.304 * * *$ & $2.138 * * *$ \\
\hline & $(0.0393)$ & $(0.0386)$ & $(0.0404)$ & $(0.0394)$ & $(0.0727)$ & $(0.0702)$ & $(0.0752)$ & $(0.0711)$ \\
\hline
\end{tabular}




\begin{tabular}{lcccccccc}
\hline $\mathrm{N}$ & 4609 & 4609 & 4609 & 4609 & 4609 & 4609 & 4609 & 4609 \\
$\mathrm{chi} 2$ & 280.8 & 279.0 & 277.3 & 283.3 & 357.4 & 372.0 & 360.4 & 376.0 \\
$\mathrm{p}$ & $1.05 \mathrm{e}-57$ & $2.62 \mathrm{e}-57$ & $5.91 \mathrm{e}-57$ & $1.48 \mathrm{e}-56$ & $4.06 \mathrm{e}-74$ & $2.93 \mathrm{e}-77$ & $8.88 \mathrm{e}-75$ & $2.53 \mathrm{e}-76$ \\
\hline
\end{tabular}

Table 5. Determinants of the Benefits of Privatization with Corporate Governance measured by the Non-SOE Dummy

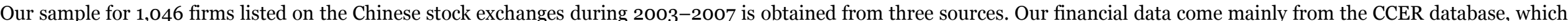

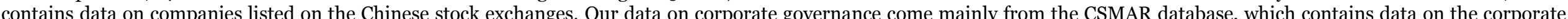

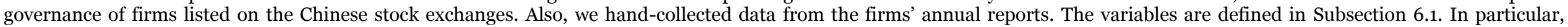

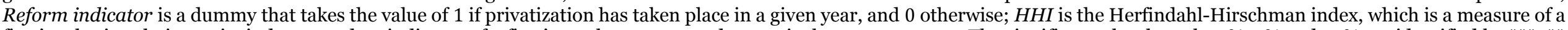

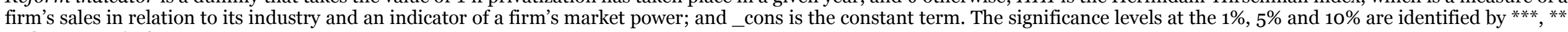
and *, respectively.

\begin{tabular}{|c|c|c|c|c|c|c|c|c|}
\hline & (1) & (2) & (3) & (4) & (5) & (6) & (7) & (8) \\
\hline & w_q & w_q & w_q & w_q & w_q & w_q & w_q & w_q \\
\hline \multirow[t]{2}{*}{ Industry Q } & $0.0738 * * *$ & $0.0802 * * *$ & $0.0759 * * *$ & $0.0766 * * *$ & $0.0722 * * *$ & $0.0745 * * *$ & $0.0742 * * *$ & $0.0719 * * *$ \\
\hline & $(0.00905)$ & $(0.00907)$ & $(0.00903)$ & $(0.00905)$ & $(0.00886)$ & $(0.00872)$ & $(0.00885)$ & $(0.00873)$ \\
\hline \multirow[t]{2}{*}{ Reform indicator } & $0.304 * * *$ & $0.308 * * *$ & $0.171 * * *$ & -0.2719 & $0.307 * * *$ & $0.637 * * *$ & $0.180 * * *$ & 0.0625 \\
\hline & $(0.0342)$ & $(0.0646)$ & $(0.0571)$ & $(0.5660)$ & $(0.0326)$ & $(0.130)$ & $(0.0561)$ & $(0.1223)$ \\
\hline \multirow[t]{2}{*}{ Non-SOE } & -0.00158 & $0.103^{* *}$ & $0.104^{* *}$ & 0.0171 & -0.0246 & $0.103 * *$ & $0.0809 *$ & 0.0202 \\
\hline & $(0.0569)$ & $(0.0495)$ & $(0.0500)$ & $(0.0563)$ & $(0.0540)$ & $(0.0458)$ & $(0.0477)$ & $(0.0520)$ \\
\hline \multirow[t]{2}{*}{ Forced turnover } & $0.0871 * *$ & $0.0894 * * *$ & 0.0194 & 0.0260 & $0.0595^{*}$ & $0.0744 * *$ & -0.0132 & 0.0128 \\
\hline & $(0.0346)$ & $(0.0346)$ & $(0.0364)$ & $(0.0365)$ & $(0.0337)$ & $(0.0345)$ & $(0.0363)$ & $(0.0373)$ \\
\hline \multirow[t]{2}{*}{ HHI } & $-0.285^{* * *}$ & $-0.227 * * *$ & $-0.288 * * *$ & $-0.234 * * *$ & & & & \\
\hline & $(0.0413)$ & $(0.0375)$ & $(0.0415)$ & $(0.0373)$ & & & & \\
\hline \multirow[t]{2}{*}{ Big } & & & & & $-1.014 * * *$ & $-0.827 * * *$ & $-1.013 * * *$ & $-0.843 * * *$ \\
\hline & & & & & $(0.0800)$ & $(0.0785)$ & $(0.0797)$ & $(0.0784)$ \\
\hline \multirow[t]{2}{*}{ Reform $\times$ Non-SOE } & $0.639 * * *$ & & & $0.597 * * *$ & $0.657 * * *$ & & & $0.575 * * *$ \\
\hline & $(0.0644)$ & & & $(0.0659)$ & $(0.0628)$ & & & $(0.0638)$ \\
\hline Reform $\times$ HHI & & $-0.160 * *$ & & $-0.130 * *$ & & & & \\
\hline
\end{tabular}




\begin{tabular}{|c|c|c|c|c|c|c|c|c|}
\hline & & $(0.0655)$ & & $(0.0646)$ & & & & \\
\hline Reform $\times$ Big & & & & & & $\begin{array}{c}-0.507 * * * \\
(0.126)\end{array}$ & & $\begin{array}{c}-0.469 * * * \\
(0.124)\end{array}$ \\
\hline Reform $\times$ Change of CEO & & & $\begin{array}{l}0.171 * * \\
(0.0701)\end{array}$ & $\begin{array}{l}0.138^{* *} \\
(0.0700)\end{array}$ & & & $\begin{array}{c}0.182 * * * \\
(0.0694)\end{array}$ & $\begin{array}{c}0.132 * \\
(0.0684)\end{array}$ \\
\hline _cons & $\begin{array}{c}1.734 * * * \\
(0.0398)\end{array}$ & $\begin{array}{l}1.661 * * * \\
(0.0391)\end{array}$ & $\begin{array}{l}1.719 * * * \\
(0.0400)\end{array}$ & $\begin{array}{l}1.720 * * * \\
(0.0396)\end{array}$ & $\begin{array}{c}2.422 * * * \\
(0.0758)\end{array}$ & $\begin{array}{c}2.229 * * * \\
(0.0758)\end{array}$ & $\begin{array}{c}2.407 * * * \\
(0.0762)\end{array}$ & $\begin{array}{c}2.294 * * * \\
(0.0759)\end{array}$ \\
\hline $\mathrm{N}$ & 5009 & 5009 & 5009 & 5009 & 5009 & 5009 & 5009 & 5009 \\
\hline chi2 & 495.7 & 274.1 & 271.5 & 468.5 & 524.9 & 345.4 & 318.1 & 501.2 \\
\hline $\mathrm{p}$ & $7.05 \mathrm{e}-104$ & $2.90 e-56$ & $1.04 \mathrm{e}-55$ & $4.06 \mathrm{e}-96$ & $3.65 \mathrm{e}-110$ & $1.52 \mathrm{e}-71$ & $1.10 \mathrm{e}-65$ & $3.87 \mathrm{e}-103$ \\
\hline
\end{tabular}




\subsection{Main Empirical Findings}

Our empirical results are summarized as follows. First, firm value is increased after privatization, as measured by both Tobin's $Q$ and buy-hold stock returns. ${ }^{16}$ This is true even after controlling for ownership structure, financial factors, stock liquidity, and growth opportunities.

Second, we incorporate the three variables $p, q$ and $\mu$ from our theoretical model into our regression model and find that these variables are significantly associated with firm value and these associations are consistent with the predictions of our theory. That is, firm value increases with the strength of internal governance and the relative importance of the manager, and decreases with external risks.

Third, the magnitude of the increase in firm value after privatization (the benefits of privatization) is determined by external risk, internal governance, and the relative importance of the manager. We generate three interaction terms between the reform indicator and the three factors. The larger the absolute value of the coefficient of an interaction term, the greater the factor's contribution to the benefits of privatization. We find that better internal governance, more external risk and greater importance of the manager will all magnify the benefits of privatization. These empirical results remain even when we use different variables as proxies.

The first empirical result is not new to the literature. The other two results have never been emphasized or shown in existing studies and also supports our theoretical findings.

\section{Concluding Remarks}

Understanding the role of ownership is key to understanding the proper role of the government in an economy. This paper analyses the contractual relationships of firms under state and private ownership. We focus on three factors: external risks, internal corruption, and relative importance of owners versus managers. The privatization literature typically ignores these factors. Our main theoretical conclusion is that the market solution is better if the business environment is risky, corruption is limited, or the manager is more important to the firm than the owner; otherwise the planning solution is better. Our conclusion agrees with Turhan's (2005) assessment in his survey that "both theoretical and empirical evidence confirms that the nature of ownership is important. Changes in managerial incentives and enterprise objectives are likely to affect the performance of enterprises."

Our empirical analysis supports our theoretical findings. Our main empirical conclusion is that the magnitude of change in firm value is significantly associated with the three key

${ }^{16}$ Here, buy-hold stock returns are used in a robustness test. Results of all robustness tests for the regression results from Tables 3 to 5 are available upon request. 
factors in our theoretical model, and the direction of change in firm value associated with each of these factors is consistent with the predictions of our theory.

Some researchers, such as Vernon-Wortzel \& Wortzel (1989) and Chang \& Singh (1997), argue that SOEs and private firms face the same set of problems, in particular organizational problems, incentive problems, business risks, and even government interference. So there is no reason why SOEs and private firms should differ in economic efficiency. We take this argument into consideration in our model setting, instead of choosing a side first and trying to argue for why state ownership is good or bad. Our model is the only theoretical model that compares optimal solutions having different ownership arrangements under the same model setting. The same incentive problem, external risk and internal corruption exist; the only difference is the ownership, which leads to different contractual relationships. Our conclusions are conditional on environmental factors, such as business risks, internal governance and the relative importance of owners versus managers. In the privatization literature, these factors are not discussed. However, these factors are important for privatization, as our theoretical and empirical analyses have indicated.

Many of the existing theoretical arguments in support of privatization argue that the government does not maximize social welfare and therefore state ownership is inefficient because of a faulty political system. In contrast, we assume that the government does maximize social welfare. It is the doctrine of "equal pay for all" that limits the government's choices, but it does not prevent the government from achieving efficiency under ideal circumstances. Instead, we emphasize certain factors that determine the differences between state and private ownership.

We also assume complete markets. Our analysis is conditional on complete markets and focuses on the contractual differences between private and state ownership. As suggested in the literature, when markets are complete, private ownership has many advantages; when markets are incomplete, state ownership has a few advantages. Markets may not be complete when economic development is still in its infancy. If the financial market is incomplete, private companies may have difficulty in obtaining funding for large and long-term projects. This is true for infrastructure projects and companies in computing industries, for example. The government can play an important role in this case. State ownership ensures funding and mitigates risks (risk sharing by all vs. risk sharing by a few investors). State ownership under incomplete markets is a broad topic in the literature, but our paper considers a well-developed economy with complete markets. Complete markets can resolve the problems of funding and risk sharing. Hence, our paper offers a unique viewpoint to the literature and addresses the question of why state ownership exists under complete markets. 


\section{Appendix}

All proofs are provided in this appendix.

\section{A.1. Proof of Proposition 1}

Notice that $a, b$, and $z$ in problem (5) are functions of $\varepsilon$. Hence, problem (5) can be more explicitly written in the following form:

$$
\begin{aligned}
\max _{a, b, z, S(\cdot)} & \int\{f[a(\varepsilon), b(\varepsilon)]+\varepsilon-s\{f[a(\varepsilon), b(\varepsilon)]+\varepsilon-z(\varepsilon)\}-(1-p) z(\varepsilon)+p \phi(z(\varepsilon))-C[b(\varepsilon)]\} d \Psi(\varepsilon) \\
\text { s.t. } \quad & s^{\prime}\{f[a(\varepsilon), b(\varepsilon)]+\varepsilon-z(\varepsilon)\} f_{a}[a(\varepsilon), b(\varepsilon)]=c^{\prime}[a(\varepsilon)], \\
& f_{b}[a(\varepsilon), b(\varepsilon)]\left\{1-s^{\prime}[f(a(\varepsilon), b(\varepsilon))+\varepsilon-z(\varepsilon)]\right\}=C^{\prime}[b(\varepsilon)], \\
& 1-p=s^{\prime}\{f[a(\varepsilon), b(\varepsilon)]+\varepsilon-z(\varepsilon)\}+p \phi^{\prime}[z(\varepsilon)], \\
& \text { SOCs, IR. }
\end{aligned}
$$

We first find that the IR condition must be binding. If not, given an optimal contract $s^{*}$, we would be able to reduce $s^{*}$ by a small fixed amount $\rho>0$ such that the IR condition would still hold. Then, all the conditions in (5) would be satisfied with this new contract $s^{*}+\rho$ and the principal's expected profit would be larger. This contradicts the fact that $s^{*}$ is an optimal contract. Hence, the IR condition must be binding. Using the binding IR condition, problem (5) becomes

$$
\begin{array}{cl}
\max _{a, b, z, S(\cdot)} & E[f(a, b)+\tilde{\varepsilon}-c(a)-C(b)] \\
\text { s.t. } & I C_{1}: s^{\prime}[f(a, b)+\tilde{\varepsilon}-z] f_{a}(a, b)=c^{\prime}(a), \\
& I C_{2}: f_{b}(a, b)\left\{1-s^{\prime}[f(a, b)+\tilde{\varepsilon}-\mathrm{z}]\right\}=C^{\prime}(b), \\
& I C_{3}: 1-p=s^{\prime}[f(a, b)+\tilde{\varepsilon}-\mathrm{z}]+p \phi^{\prime}(z),
\end{array}
$$

SOCs: Two SOCs for (1) and one SOC for (3),

$I R: E\{s[f(a, b)+\tilde{\varepsilon}-z]-c(a)+(1-p) z-p \phi(z)\}=0$.

From the $I C_{1}$ condition in (31), we can solve for $s^{\prime}$ and substitute it into the other two IC conditions. Then, the problem becomes

$$
\begin{aligned}
\max _{a, b, z, s(\cdot)} & f(a, b)-c(a)-C(b) \\
\text { s.t. } & s^{\prime}[f(a, b)+\varepsilon-z]=\frac{c^{\prime}(a)}{f_{a}(a, b)}, \\
& \frac{c^{\prime}(a)}{f_{a}(a, b)}+\frac{C^{\prime}(b)}{f_{b}(a, b)}=1, \\
& \frac{c^{\prime}(a)}{f_{a}(a, b)}+p\left[1+\phi^{\prime}(z)\right]=1, \\
& \text { SOCs, IR. }
\end{aligned}
$$

Since the objective function does not involve the contract, this problem can be solved in four steps. First, by the Hamilton approach, we solve for $(a, b)$ from the following problem: 


$$
\begin{aligned}
& \max _{a, b \geq 0} f(a, b)-c(a)-C(b) \\
& \text { s.t. } \frac{c^{\prime}(a)}{f_{a}(a, b)}+\frac{C^{\prime}(b)}{f_{b}(a, b)}=1 .
\end{aligned}
$$

This solution to $(a, b)$ turns out to be independent of $\varepsilon$. Second, given $(a, b)$, determine $z$ from the following equation:

$$
\frac{c^{\prime}(a)}{f_{a}(a, b)}+p\left[1+\phi^{\prime}(z)\right]=1
$$

This $z$ is also independent of $\varepsilon$. Third, given $(a, b, z)$, find a contract $s(\cdot)$ satisfying the IR and the following equation:

$$
s^{\prime}[f(a, b)+\varepsilon-z]=\frac{c^{\prime}(a)}{f_{a}(a, b)} .
$$

Finally, we verify the SOCs.

In the third step, let us try to find an optimal linear contract of the form $s(x)=\alpha+\theta x$, where $\alpha$ and $\theta$ are two constants, $\alpha \in \mathbb{R}$ and $\theta \in[0,1]$. By (34),

$$
\theta=\frac{c^{\prime}(a)}{f_{a}(a, b)}
$$

By the constraint in (32), we know that this $\theta$ is in $(0,1)$. Next, by the IR condition, this $\alpha$ is defined by

$$
\alpha=E\{c(a)-(1-p) z+p \phi(z)-\theta[f(a, b)+\tilde{\varepsilon}-z]\} .
$$

This means that there is a linear contract that satisfies (34) and the IR condition.

Finally, for this linear contract, we can easily verify the three SOCs. Hence, we have Proposition 1.

\section{A.2. Lemma 1}

Lemma 1. Given $\gamma \leq 1$, if the two inputs $a$ and $b$ are complementary, i.e., $f_{a b}(a, b) \geq 0$, and $f(a, b)$ and $C(b)$ are twice differentiable, then problem (37)

$$
\begin{array}{rl}
\max _{a, b} & f(a, b)-c(a)-C(b) \\
\text { s.t. } & f_{b}(a, b)=C^{\prime}(b), \\
& (1-\gamma) f_{a}(a, b)=c^{\prime}(a) .
\end{array}
$$

is equivalent to problem (38)

$$
\begin{array}{rl}
\max _{a, b} & f(a, b)-c(a)-C(b) \\
\text { s.t. } & f_{b}(a, b) \geq C^{\prime}(b), \\
& (1-\gamma) f_{a}(a, b) \geq c^{\prime}(a) .
\end{array}
$$


Proof. We need to show that, for any solution to (38), the two inequality constraints must be binding. If a solution $(\hat{a}, \hat{b})$ of $(38)$ satisfies $f_{b}(\hat{a}, \hat{b})>C^{\prime}(\hat{b})$, by the continuity of $f_{b}$ and $C^{\prime}$, we can find an $\varepsilon>0$ such that

$$
f_{b}(\hat{a}, \hat{b}+\varepsilon) \geq C^{\prime}(\hat{b}+\varepsilon) .
$$

Since $a$ and $b$ are complementary in production, the fact that

$$
(1-\gamma) f_{a}(\hat{a}, \hat{b}) \geq c^{\prime}(\hat{a})
$$

implies that

$$
(1-\gamma) f_{a}(\hat{a}, \hat{b}+\varepsilon) \geq c^{\prime}(\hat{a})
$$

We know that, given $\hat{a}$, the optimal $b^{*}$ that maximizes $\phi(b) \equiv f(\hat{a}, b)-c(\hat{a})-C(b)$ without any constraint satisfies condition $f_{b}\left(\hat{a}, b^{*}\right)=C^{\prime}\left(b^{*}\right)$. Since $\phi(b)$ is concave and is maximized at $b^{*}, \phi(b)$ is increasing in $\left[0, b^{*}\right]$ and decreasing in $\left[b^{*},+\infty\right)$. With $f_{b}(\hat{a}, \hat{b})>C^{\prime}(\hat{b})$ or $\phi^{\prime}(\hat{b})>0$, as shown in the following figure, we have $\hat{b} \in\left[0, b^{*}\right)$.

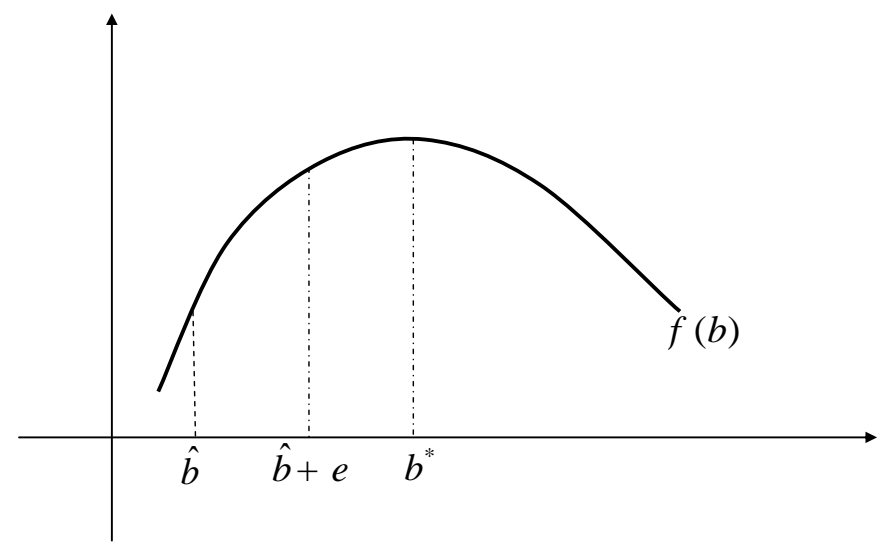

Figure 3. A Concave Curve

Assume that $\hat{b}+\varepsilon \leq b^{*}$, which can be done by choosing a sufficiently small $\varepsilon$ in (39). Hence, $\phi(\hat{b}+\varepsilon)>\phi(\hat{b})$. This means that $(\hat{a}, \hat{b}+\varepsilon)$ satisfies the two conditions in (38), as shown in (39) and (40), and yields a higher value to problem (38). This contradicts the fact that $(\hat{a}, \hat{b})$ is a solution to (38). Symmetrically, the second constraint must also be binding. This means that the more relaxed constraints in (38) do not improve the maximum value of $f(a, b)-c(a)-$ $C(b)$. Therefore, problems (37) and (38) are equivalent.

\section{A.3. Lemma 2}

Lemma 2. If a function $f(a, b)$ is concave and strictly increasing, $f_{a b}(a, b) \geq 0$, and $c(a)$ and $C(b)$ are strictly convex, then, for any constant $A$ and increasing function $\varphi: \mathbb{R} \rightarrow \mathbb{R}$, the solution $\left(a^{*}, b^{*}\right)$ to the following equation system is strictly decreasing in $\varepsilon$ : 


$$
\left\{\begin{array}{l}
f_{b}(a, b)=C^{\prime}(b) \\
\{A-\varphi[f(a, b)+\varepsilon]\} f_{a}(a, b)=c^{\prime}(a)
\end{array}\right.
$$

Proof: The equation system determines a pair $(a(\varepsilon), b(\varepsilon))$. Taking the derivative with respect to $\varepsilon$ on the equation system yields:

$$
\begin{aligned}
& f_{a b}(a, b) a^{\prime}+f_{b b}(a, b) b^{\prime}=C^{\prime \prime}(b) b^{\prime}, \\
& {[A-\varphi(f+\varepsilon)]\left[f_{a a}(a, b) a^{\prime}+f_{a b}(a, b) b^{\prime}\right]-\left(f_{a} a^{\prime}+f_{b} b^{\prime}+1\right) \varphi^{\prime} f_{a}=c^{\prime \prime}(a) a^{\prime},}
\end{aligned}
$$

implying that

$$
\left(\begin{array}{cc}
f_{a b} & f_{b b}-C^{\prime \prime}(b) \\
{[A-\varphi(f+\varepsilon)] f_{a a}-f_{a}{ }^{2} \varphi^{\prime}-c^{\prime \prime}(a)} & {[A-\varphi(f+\varepsilon)] f_{a b}-\varphi^{\prime} f_{a} f_{b}}
\end{array}\right)\left(\begin{array}{c}
a^{\prime} \\
b^{\prime}
\end{array}\right)=\left(\begin{array}{c}
0 \\
\varphi^{\prime} f_{a}
\end{array}\right),
$$

implying that

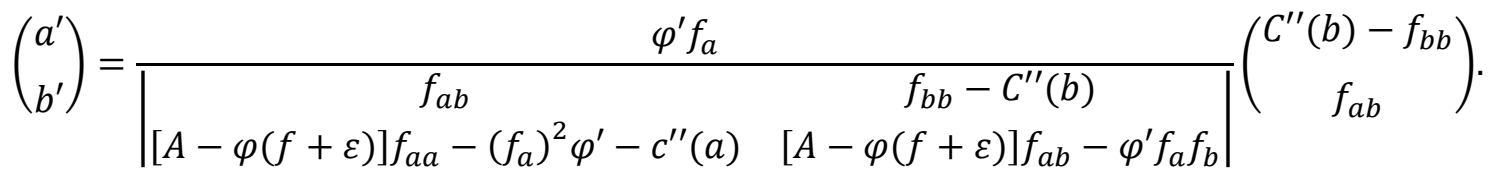

We have

$$
\begin{aligned}
& \left|\begin{array}{cc}
f_{a b} & f_{b b}-C^{\prime \prime}(b) \\
{[A-\varphi(f+\varepsilon)] f_{a a}-f_{a}{ }^{2} \varphi^{\prime}-c^{\prime \prime}(a)} & {[A-\varphi(f+\varepsilon)] f_{a b}-\varphi^{\prime} f_{a} f_{b}}
\end{array}\right| \\
= & {[A-\varphi(f+\varepsilon)]\left(f_{a b}\right)^{2}-\varphi^{\prime} f_{a} f_{b} f_{a b}-\left\{[A-\varphi(f+\varepsilon)] f_{a a}-\left(f_{a}\right)^{2} \varphi^{\prime}-c^{\prime \prime}(a)\right\}\left[f_{b b}-C^{\prime \prime}(b)\right] } \\
= & {[A-\varphi(f+\varepsilon)]\left[\left(f_{a b}\right)^{2}-f_{a a} f_{b b}\right]-\varphi^{\prime} f_{a} f_{b} f_{a b}+\left[\left(f_{a}\right)^{2} \varphi^{\prime}+c^{\prime \prime}(a)\right] f_{b b} } \\
& +\left\{[A-\varphi(f+\varepsilon)] f_{a a}-\left(f_{a}\right)^{2} \varphi^{\prime}-c^{\prime \prime}(a)\right\} C^{\prime \prime}(b)<0,
\end{aligned}
$$

where concavity of $f(a, b)$ implies

$$
f_{a a} \leq 0, \quad f_{b b} \leq 0, \quad f_{a a} f_{b b}-\left(f_{a b}\right)^{2} \geq 0,
$$

and the second equation of (41) implies $A-\varphi(f+\varepsilon) \geq 0$. Hence,

$$
\frac{\partial a}{\partial \varepsilon}<0, \quad \frac{\partial b}{\partial \varepsilon} \leq 0
$$

\section{A.4. Lemma 3}

Lemma 3. If a function $f(a, b)$ is concave and strictly increasing, $f_{a b}(a, b) \geq 0, c(a)$ and $C(b)$ are strictly convex and $\phi$ is convex, given the fact that the manager will aim for the high pay in good times and $x_{0}=f\left(a_{g, h}, b_{g, h}\right)+\varepsilon_{g}$, the manager will aim for the low pay in bad times.

Proof: Given $b_{b, h}$, if the manager aims for the high pay in bad times, her problem in bad times is

$$
\begin{gathered}
\max _{a, z \geq 0} s_{h}-c(a)+(1-p) z-p \phi(z) \\
\text { s.t. } f\left(a, b_{b, h}\right)+\varepsilon_{b}-z \geq x_{0} .
\end{gathered}
$$

Consider the following equation: 


$$
f_{b}(a, b)=C^{\prime}(b)
$$

which determines $b$ as a function of $a$. From this equation, we find

$$
\frac{d b}{d a}=\frac{f_{a b}(a, b)}{C^{\prime \prime}(b)-f_{b b}(a, b)} \geq 0 .
$$

If the constraint in (42) is nonbinding at its optimal, the derivative of the objective function with respect to $a$ is negative, implying $a_{b, h}=0$. Since $x_{0}=f\left(\hat{a}_{g, h}, \hat{b}_{g, h}\right)+\varepsilon_{g}$, the inequality constraint in (42) becomes

$$
f\left(0, b_{b, h}\right)+\varepsilon_{b}-z>f\left(\hat{a}_{g, h}, \hat{b}_{g, h}\right)+\varepsilon_{g}
$$

By (17), we have $f_{b}\left(a_{g, h}, b_{g, h}\right)=C^{\prime}\left(b_{g, h}\right)$ and $f_{b}\left(a_{b, h}, b_{b, h}\right)=C^{\prime}\left(b_{b, h}\right)$. Since $a_{b, h}=0 \leq a_{g, h}$, by (43), we have $b_{g, h} \geq b_{b, h}$. Since $\varepsilon_{g}>\varepsilon_{b}$, the inequality in (44) in impossible.

Hence, the constraint in (42) must be binding at its optimal, and the Nash equilibrium $\left(a_{b, h}, b_{b, h}\right)$ is determined by

$$
\begin{aligned}
& f_{b}\left(a_{b, h}, b_{b, h}\right)=C^{\prime}\left(b_{b, h}\right), \\
& \left(1-p-p \phi^{\prime}\left[f\left(a_{b, h}, b_{b, h}\right)+\varepsilon_{b}-x_{0}\right]\right) f_{a}\left(a_{b, h}, b_{b, h}\right)=c^{\prime}\left(a_{b, h}\right),
\end{aligned}
$$

where the first equation is from (17) and the second equation from (42). In contrast, from (23), the Nash equilibrium $\left(a_{g, h}, b_{g, h}\right)$ is determined by

$$
\begin{aligned}
& f_{b}\left(a_{g, h}, b_{g, h}\right)=C^{\prime}\left(b_{g, h}\right), \\
& \left(1-p-p \phi^{\prime}\left[f\left(a_{g, h}, b_{g, h}\right)+\varepsilon_{g}-x_{0}\right]\right) f_{a}\left(a_{g, h}, b_{g, h}\right)=c^{\prime}\left(a_{g, h}\right),
\end{aligned}
$$

Comparing the solution $\left(a_{b, h}, b_{b, h}\right)$ from (45) with the solution $\left(a_{g, h}, b_{g, h}\right)$ from (46), since $\varepsilon_{b}<$ $\varepsilon_{g}$, Lemma 2 shows that $\left(a_{b, h}, b_{b, h}\right)<\left(a_{g, h}, b_{g, h}\right)$, implying $f\left(a_{b, h}, b_{b, h}\right)<f\left(a_{g, h}, b_{g, h}\right)$. Given $x_{0}$ defined by $x_{0}=f\left(\hat{a}_{g, h}, \hat{b}_{g, h}\right)+\varepsilon_{g}$, we find

$$
f\left(a_{b, h}, b_{b, h}\right)+\varepsilon_{b}<x_{0}
$$

implying that the manager does not receive the high pay since output is less than $x_{0}$ in this case. This contradicts the assumption that the manager is aiming for the high pay. In fact, the manager will be aiming for the low pay in bad times.

\section{A.5. Proof of Proposition 2}

To solve the problem, we first drop $z_{g, h}$ and $z_{b, l}$ from problem (23) since they are determined by

$$
z_{g, h}=f\left(a_{g, h}, b_{g, h}\right)+\varepsilon_{g}-x_{0}, \quad \phi^{\prime}\left(z_{b, l}\right)=\frac{1-p}{p} .
$$

Similarly, we can also drop $a_{b, l}$ and $b_{b, l}$. Then, problem (23) becomes 


$$
\begin{array}{ll}
\underset{a_{g, h}, b_{g, h}, S_{l}, s_{h}, x_{0} \geq 0}{\text { s.t. }} & W \\
& f_{b}\left(a_{g, h}, b_{g, h}\right)=C^{\prime}\left(b_{g, h}\right), \\
& \frac{c^{\prime}\left(a_{g, h}\right)}{f_{a}\left(a_{g, h}, b_{g, h}\right)}+p\left\{1+\phi^{\prime}\left[f\left(a_{g, h}, b_{g, h}\right)+\varepsilon_{g}-x_{0}\right]\right\}=1, \\
& f\left(a_{g, h}, b_{g, h}\right)+\varepsilon_{g}-x_{0} \geq 0,
\end{array}
$$

IC condition (20),

IR condition (22).

Again, the IR condition must be binding. If not, we would be able to reduce $s_{h}-s_{l}$ by a tiny amount such that all conditions are satisfied but social welfare is increased, which is a contradiction. With the binding IR condition, we find

$$
\begin{aligned}
W= & q\left\{f\left(a_{g, h}, b_{g, h}\right)-s_{h}-(1-p) z_{g, h}+p \phi\left(z_{g, h}\right)-C\left(b_{g, h}\right)\right\} \\
& +(1-q)\left\{f\left(0, b_{b, l}\right)-s_{l}-(1-p) z_{b, l}+p \phi\left(z_{b, l}\right)-C\left(b_{b, l}\right)\right\}+\bar{\varepsilon} \\
= & q\left\{f\left(a_{g, h}, b_{g, h}\right)-c\left(a_{g, h}\right)-C\left(b_{g, h}\right)\right\}+(1-q)\left\{f\left(0, b_{b, l}\right)-C\left(b_{b, l}\right)\right\} \\
& -q\left[s_{h}-c\left(a_{g, h}\right)+(1-p) z_{g, h}-p \phi\left(z_{g, h}\right)\right]-(1-q)\left\{s_{l}+(1-p) z_{b, l}-p \phi\left(z_{b, l}\right)\right\}+\bar{\varepsilon} \\
= & q\left[f\left(a_{g, h}, b_{g, h}\right)-c\left(a_{g, h}\right)-C\left(b_{g, h}\right)\right]+(1-q)\left[f\left(0, b_{b, l}\right)-C\left(b_{b, l}\right)\right]+\bar{\varepsilon} .
\end{aligned}
$$

Then, the problem becomes

$$
\begin{array}{cl}
\max _{a_{g, h}, b_{g, h}, s_{l}, s_{h}, x_{0} \geq 0} q\left[f\left(a_{g, h}, b_{g, h}\right)-c\left(a_{g, h}\right)-C\left(b_{g, h}\right)\right]+(1-q)\left[f\left(0, b_{b, l}\right)-C\left(b_{b, l}\right)\right]+\bar{\varepsilon} \\
\text { s.t. } \quad & f_{b}\left(a_{g, h}, b_{g, h}\right)=C^{\prime}\left(b_{g, h}\right), \\
& \frac{c^{\prime}\left(a_{g, h}\right)}{f_{a}\left(a_{g, h}, b_{g, h}\right)}+p\left\{1+\phi^{\prime}\left[f\left(a_{g, h}, b_{g, h}\right)+\varepsilon_{g}-x_{0}\right]\right\}=1, \\
& f\left(a_{g, h}, b_{g, h}\right)+\varepsilon_{g}-x_{0} \geq 0,
\end{array}
$$

IC condition (20),

IR condition (22).

Since $s_{h}$ and $s_{l}$ are not part of the objective function of (47), we can drop $s_{h}$ and $s_{l}$. We will also drop the IC and IR conditions; we will later choose $s_{h}$ and $s_{l}$ to satisfy the IC and IR conditions. Then, problem (47) becomes

$$
\begin{array}{rl}
\max _{a_{g, h}, b_{g, h}, x_{0} \geq 0} & f\left(a_{g, h}, b_{g, h}\right)-c\left(a_{g, h}\right)-C\left(b_{g, h}\right) \\
\text { s.t. } & f_{b}\left(a_{g, h}, b_{g, h}\right)=C^{\prime}\left(b_{g, h}\right), \\
& \frac{c^{\prime}\left(a_{g, h}\right)}{f_{a}\left(a_{g, h}, b_{g, h}\right)}+p\left\{1+\phi^{\prime}\left[f\left(a_{g, h}, b_{g, h}\right)+\varepsilon_{g}-x_{0}\right]\right\}=1, \\
& x_{0} \leq f\left(a_{g, h}, b_{g, h}\right)+\varepsilon_{g} .
\end{array}
$$

By Lemma 1, problem (48) is equivalent to the following problem:

$$
\begin{array}{rl}
\max _{a_{g, h}, b_{g, h}, x_{0} \geq 0} & f\left(a_{g, h}, b_{g, h}\right)-c\left(a_{g, h}\right)-C\left(b_{g, h}\right) \\
\text { s.t. } \quad & f_{b}\left(a_{g, h}, b_{g, h}\right) \geq C^{\prime}\left(b_{g, h}\right), \\
& \left(1-p\left\{1+\phi^{\prime}\left[f\left(a_{g, h}, b_{g, h}\right)+\varepsilon_{g}-x_{0}\right]\right\}\right) f_{a}\left(a_{g, h}, b_{g, h}\right) \geq c^{\prime}\left(a_{g, h}\right), \\
& x_{0} \leq f\left(a_{g, h}, b_{g, h}\right)+\varepsilon_{g} .
\end{array}
$$

Given $x_{0}$, its Lagrange function is 


$$
\begin{aligned}
L= & f\left(a_{g, h}, b_{g, h}\right)-c\left(a_{g, h}\right)-C\left(b_{g, h}\right)+\lambda\left[f_{b}\left(a_{g, h}, b_{g, h}\right)-C^{\prime}\left(b_{g, h}\right)\right] \\
& +\mu\left[\left(1-p\left\{1+\phi^{\prime}\left[f\left(a_{g, h}, b_{g, h}\right)+\varepsilon_{g}-x_{0}\right]\right\}\right) f_{a}\left(a_{g, h}, b_{g, h}\right)-c^{\prime}\left(a_{g, h}\right)\right],
\end{aligned}
$$

where $\lambda \geq 0$ and $\mu \geq 0$ are the Lagrange multipliers. Then, the FOCs for $a_{g, h}$ and $b_{g, h}$ are respectively

$$
\begin{aligned}
0=\frac{\partial L}{\partial a_{g, h}}= & f_{a}\left(a_{g, h}, b_{g, h}\right)-c^{\prime}\left(a_{g, h}\right)+\lambda f_{a b}\left(a_{g, h}, b_{g, h}\right) \\
& +\mu\left\{-p \phi^{\prime \prime}\left[f\left(a_{g, h}, b_{g, h}\right)+\varepsilon_{g}-x_{0}\right]\left[f_{a}\left(a_{g, h}, b_{g, h}\right)\right]^{2}-c^{\prime \prime}\left(a_{g, h}\right)\right\} \\
0=\frac{\partial L}{\partial b_{g, h}}= & f_{b}\left(a_{g, h}, b_{g, h}\right)-C^{\prime}\left(b_{g, h}\right)+\lambda\left[f_{b b}\left(a_{g, h}, b_{g, h}\right)-C^{\prime \prime}\left(b_{g, h}\right)\right] \\
& +\mu\left\{-p \phi^{\prime \prime}\left[f\left(a_{g, h}, b_{g, h}\right)+\varepsilon_{g}-x_{0}\right] f_{b}\left(a_{g, h}, b_{g, h}\right) f_{a}\left(a_{g, h}, b_{g, h}\right)\right\}
\end{aligned}
$$

By the first constraint in (48), the second FOC in (49) implies that

$$
\begin{aligned}
\lambda\left[f_{b b}\left(a_{g, h}, b_{g, h}\right)\right. & \left.-C^{\prime \prime}\left(b_{g, h}\right)\right] \\
& +\mu\left\{-p \phi^{\prime \prime}\left[f\left(a_{g, h}, b_{g, h}\right)+\varepsilon_{g}-x_{0}\right] f_{b}\left(a_{g, h}, b_{g, h}\right) f_{a}\left(a_{g, h}, b_{g, h}\right)\right\}=0 .
\end{aligned}
$$

This implies that, if $\mu=0$, we must have $\lambda=0$. If so, the first FOC in (49) would imply that

$$
f_{a}\left(a_{g, h}, b_{g, h}\right)=c^{\prime}\left(a_{g, h}\right),
$$

which contradicts the second constraint in (47). Hence, we must have $\mu \neq 0$, i.e., $\mu>0$. Then, by (50) again, we have $\lambda \neq 0$, i.e., $\lambda>0$. By $\mu>0$, we find

$$
\frac{\partial L}{\partial x_{0}}=\mu p \phi^{\prime \prime}\left[f\left(a_{g, h}, b_{g, h}\right)+\varepsilon_{g}-x_{0}\right] f_{a}\left(a_{g, h}, b_{g, h}\right)>0 .
$$

Hence, the optimal $x_{0}$ is

$$
\widehat{x}_{0}=f\left(a_{g, h}, b_{g, h}\right)+\varepsilon_{g} .
$$

Then, by (14), $\hat{z}_{g, h}=0$. After $x_{0}$ is determined from (51), problem (48) becomes

$$
\begin{array}{rl}
\max _{a_{g, h}, b_{g, h}} & f\left(a_{g, h}, b_{g, h}\right)-c\left(a_{g, h}\right)-C\left(b_{g, h}\right) \\
\text { s.t. } & f_{b}\left(a_{g, h}, b_{g, h}\right)=C^{\prime}\left(b_{g, h}\right), \\
& \frac{c^{\prime}\left(a_{g, h}\right)}{f_{a}\left(a_{g, h}, b_{g, h}\right)}+p\left[1+\phi^{\prime}(0)\right]=1 .
\end{array}
$$

In this problem, the two constraints have already determined the solution, i.e., $\left(\hat{a}_{g, h}, \hat{b}_{g, h}\right)$ is the solution to the following equations:

$$
f_{b}\left(a_{g, h}, b_{g, h}\right)=C^{\prime}\left(b_{g, h}\right), \quad \frac{c^{\prime}\left(a_{g, h}\right)}{f_{a}\left(a_{g, h}, b_{g, h}\right)}+p\left[1+\phi^{\prime}(0)\right]=1 .
$$

With this $\left(\hat{a}_{g, h}, \hat{b}_{g, h}\right),(51)$ then determines the optimal $x_{0}$ :

$$
\hat{x}_{0}=f\left(\hat{a}_{g, h}, \hat{b}_{g, h}\right)+\varepsilon_{g} .
$$

Hence, the solution $\left(\hat{a}_{g, h}, \hat{b}_{g, h}, \hat{x}_{0}\right)$ of (48) is determined from (52)-(53). Note here that Lemma 1 requires the following condition: $p\left[1+\phi^{\prime}(0)\right] \leq 1$.

Finally, since $\hat{z}_{g, h}=0$, condition (20) becomes 


$$
s_{h}-s_{l} \geq(1-p) z_{g, l}-p \phi\left(z_{g, l}\right)+c\left(a_{g, h}\right) .
$$

Also, the binding IR condition (22) becomes

$$
\bar{s}+(1-q)\left[(1-p) z_{b, l}-p \phi\left(z_{b, l}\right)\right]-q c\left(a_{g, h}\right)=0 .
$$

We can easily find a pair of $\left(s_{h}, s_{l}\right)$ that satisfy (54) and (55). For example, we can arbitrarily find two numbers $s_{0}$ and $\Delta$ such that

$$
\begin{aligned}
& \Delta \geq(1-p) z_{g, l}-p \phi\left(z_{g, l}\right)+c\left(a_{g, h}\right), \\
& s_{0}=q c\left(a_{g, h}\right)-(1-q)\left[(1-p) z_{b, l}-p \phi\left(z_{b, l}\right)\right] .
\end{aligned}
$$

Then, define

$$
s_{l}=s_{0}-q \Delta, \quad s_{h}=s_{0}+(1-q) \Delta .
$$

This pair will satisfy (54) and (55). Notice that by (12) we have $z_{b, l}=z_{g, l}$; we can thus replace $z_{g, l}$ in (54) by $z_{b, l}$. Therefore, the optimal solution under central planning can be found and is summarized in Proposition 2.

\section{A.6. Proof of Proposition 3}

We have $W^{*} \geq \widehat{W}$ if and only if

$$
\frac{\mu_{1}^{2} \mu_{2}^{2}+\mu_{1}^{4}+\mu_{2}^{4}}{2\left(\mu_{1}^{2}+\mu_{2}^{2}\right)} \geq \frac{q}{2}\left(1-p^{2}\right) \mu_{1}^{2}+\frac{1}{2} \mu_{2}^{2},
$$

which is equivalent to

$$
\mu_{1}^{2} \mu_{2}^{2}+\mu_{1}^{4}+\mu_{2}^{4} \geq q\left(1-p^{2}\right) \mu_{1}^{2}\left(\mu_{1}^{2}+\mu_{2}^{2}\right)+\mu_{2}^{2}\left(\mu_{1}^{2}+\mu_{2}^{2}\right)
$$

or

$$
\mu_{1}^{4} \geq q\left(1-p^{2}\right) \mu_{1}^{2}\left(\mu_{1}^{2}+\mu_{2}^{2}\right)
$$

or

$$
\mu_{1}^{2} \geq q\left(1-p^{2}\right)\left(\mu_{1}^{2}+\mu_{2}^{2}\right)
$$

or

$$
q\left(1-p^{2}\right)\left(1+\left(\frac{\mu_{2}}{\mu_{1}}\right)^{2}\right) \leq 1
$$

or

$$
\frac{\mu_{2}}{\mu_{1}} \leq \sqrt{\frac{1}{q\left(1-p^{2}\right)}-1}
$$

This condition is likely to hold if $q$ is small, $p$ is large or $\mu_{2} / \mu_{1}$ is small. That is, the market solution is better if the environment is risky, corruption is limited, or the role of the owner relative to the manager is minor.

Part (a): Condition (56) is likely to hold if $q$ is small. More specifically, (56) holds if 


$$
q \leq \frac{1}{\left(1-p^{2}\right)\left(1+\left(\frac{\mu_{2}}{\mu_{1}}\right)^{2}\right)} .
$$

That is, the market solution is better if the environment is risky.

Part (b): Condition (56) holds if $\mu_{2} / \mu_{1}$ is small. Hence, the market solution is better if the role of the manager, as measured by $\mu_{1} / \mu_{2}$, is important.

Part (c): Condition (56) can be written as

$$
p \geq \sqrt{1-\frac{1}{q\left[1+\left(\frac{\mu_{2}}{\mu_{1}}\right)^{2}\right]}} .
$$

This means that, if corruption can be effectively controlled such that (57) is satisfied, then the market solution is better. When $q$ is large enough such that $q\left[1+\left(\frac{\mu_{2}}{\mu_{1}}\right)^{2}\right] \geq 1$, we can also find a $p \in[0,1]$ such that (57) is satisfied. Hence, if the environment is not very risky, the market solution is always better if corruption can be properly controlled. In particular, if $p \rightarrow 1,(56)$ is always satisfied.

Part (d): Following part (c), since $\sqrt{1-\frac{1}{q\left[1+\left(\mu_{2} / \mu_{1}\right)^{2}\right]}}$ is increasing in $q$, for a larger $q$, condition (57) requires a larger $p$. That is, the market solution requires that a safer environment (a larger $q$ ) be associated with more effective control of corruption (a larger $p$ ).

\section{A.7. The First Best}

If $a, b$ and $z$ are all verifiable, we have the first-best problem, which is problem (31) without the IC conditions and SOCs, i.e.,

$$
\begin{aligned}
& \max _{a, b, z, s(\cdot)} E[f(a, b)+\tilde{\varepsilon}-c(a)-C(b)] \\
& \text { s.t. } I R: E\{s[f(a, b)+\tilde{\varepsilon}-z]-c(a)+(1-p) z-p \phi(z)\}=0 .
\end{aligned}
$$

A solution to this problem is called a first-best solution; and correspondingly a solution to problem (31) is called a second-best solution. We use superscript $* *$ to indicate the first-best solution.

This problem can be solved in three steps. First, find $\left(a^{* *}, b^{* *}\right)$ from the following problem:

$$
\max _{a, b} f(a, b)-c(a)-C(b) .
$$

Hence, $\left(a^{* *}, b^{* *}\right)$ is determined from the following FOCs: 


$$
f_{a}\left(a^{* *}, b^{* *}\right)=c^{\prime}\left(a^{* *}\right), \quad f_{b}\left(a^{* *}, b^{* *}\right)=C^{\prime}\left(b^{* *}\right) .
$$

Second, set $z^{* *}=0$. Third, simply choose a fixed contract $s^{* *}(x)=\alpha^{* *}$, where $\alpha^{* *} \in \mathbb{R}$, to satisfy the IR condition.

By comparing (58) with the constraint in problem (6), we know that the second-best solution is strictly inferior to the first best.

For the parametric case in (25), the first-best solution is

$$
a^{* *}=\mu_{1}, \quad b^{* *}=\mu_{2}, \quad z^{* *}=0 .
$$

Social welfare is

$$
W^{* *}=\frac{\mu_{1}^{2}+\mu_{2}^{2}}{2}
$$

\section{References}

Amihud, Y. (2002), "Illiquidity and stock returns: cross-section and time-series effects," Journal of Financial Markets, 5 (1), 31-56.

Anderson, R.C. and Reeb, D.M. (2003), "Founding-Family Ownership and Firm Performance: Evidence from the S\&P 500,” Journal of Finance, 58 (3), 1301-1327.

Ang, J.S., Cole, R.A. and Lin, J.W. (2000), “Agency costs and ownership structure,” Journal of Finance, 81-106.

Allayannis, G. and Weston, J.P. (2001), "The Use of Foreign Currency Derivatives and Firm Market Value,” Review of Financial Studies, 14 (1), 243-276.

Aussenegg, W. and Jelic, R. (2006). "Does private ownership always improve firm performance? The case of Central European Transition Economies.” Working Paper.

Bai, C.-E., Li, D., Tao, Z. and Wang, Y. (2000). “A Multitask Theory of State Enterprise Reform.” Journal of Comparative Economics, 28, 716-738.

Bai, C.-E and Xu, L.C. (2005). "Incentives for CEOs with multitasks: Evidence from Chinese state-owned enterprises.” Journal of Comparative Economics, 33, 517-539.

Beck, T., Demirgüç-Kunt, A. and Maksimovic, V. (2005), "Financial and Legal Constraints to Growth: Does Firm Size Matter?,” Journal of Finance, 60 (1), 137-177.

Berger, P.G. and Ofek, E. (1995), “Diversification's effect on firm value,” Journal of Financial Economics, 37 (1), 39-65.

Bonin, J.P. and Wachtel, P. (2003), "Financial sector development in transition economies: Lessons from the first decade," Financial Markets, Institutions and Instruments, 12 (1), $1-66$. 
Boubakri, N., Cosset, J.-C. and Guedhami, O. (2005a). "Liberalization, corporate governance and the performance of privatized firms in developing countries." Journal of Corporate Finance, 11, 767-790.

Boubakri, N., Cosset, J.-C. and Guedhami, O. (2005b). "Post privatization corporate governance: The role of ownership structure and investor protection." Journal of Financial Economics, 76, 369-399.

Caves, D.W. and Christensen, L.R. (1980). "The relative efficiency of public and private firms in a competitive environment: the case of Canadian railroads." Journal of Political Economy, 88, 958-976.

Chang, H. and Singh, A. (1997). "Can Large Firms Be Run Efficiently Without Being Bureaucratic?” Journal of International Development, 9 (6), 865-75.

Chen, S.; Wang, S.; Yang, H. (2015): "Spatial Competition and Interdependence in Strategic Decisions: Empirical Evidence from Franchising.” Economic Geography, forthcoming.

Chung, K. and Pruitt, S.W. (1995), “A simple approximation of Tobin's Q, Financial Management," 57 (3), 70-74.

Daines, R. (2001), “Does Delaware law improve firm value?” Journal of Financial Economics, 62 (3), 525-558.

D’Souza, J., Megginson, and Nash, W.R. (2005). "Effect of institutional and firm-specific characteristics on post-privatization performance: Evidence from developed countries." Journal of Corporate Finance, 11, 747-766.

Ehrlich, I.; Gallais-Hamonno, G.; Liu, Z. and Lutter, R. (1994). "Productivity Growth and Firm Ownership: An Empirical Investigation,” Journal of Political Economy, 102, 1006-38.

Eisenberg, M.A. (1997). "The Board of Directors and Internal Controls," Cardozo Law Review, 19(1/2), 237-264.

Fama, E.F. and French, K.R. (1998). "Value versus Growth: The International Evidence." Journal of Finance, 53(6), 1975-1999.

Groves, T.; Hong, Y. and Naughton, B. (1995). "China's Evolving Managerial Labor Market.” Journal of Political Economy, 103 (4), 873-892.

Gupta, N. (2005). "Partial Privatization and Firm Performance." Journal of Finance, LX (2), 987-1015.

Jensen, M.C. (1986), “Agency Cost Of Free Cash Flow, Corporate Finance, and Takeovers," American Economic Review, 76 (2), 323-329.

Jiang, K.; Wang, S. (2012): "Staged Privatization: A Market Process with Multistage Lockups,” China Economic Review, 23(4), 1051-1070. 
Jones, L.P. (1985). "Public Enterprise For Whom? Perverse Distributional Consequences of Public Operational Decisions", Economic Development and Cultural Change, 33 (2), 33347.

Kalcheva, I. and Lins, K.V. (2007), "International Evidence on Cash Holdings and Expected Managerial Agency Problems,” Review of Financial Studies, 20 (4), 1087-1112.

Kazmier, L.J. and Pohl, N.F. (1984), Basic Statistics for Business and Economics, 2nd Ed., McGraw-Hill, New York.

Kole, S.R. and Mulherin, J.H. (1997). "The government as shareholder: a case from the US.” Journal of Law and Economics, 40, 1-22.

Laporta, R., Lopez-De-Silanes, F., Shleifer, A. and Vishny, R. (2002), "Investor Protection and Corporate Valuation,” Journal of Finance, 57 (3), 1147-1170.

Lemmon, M.L. and Lins, K.V. (2003), "Ownership Structure, Corporate Governance, and Firm Value: Evidence from the East Asian Financial Crisis,” Journal of Finance, 58 (4), 14451468.

Li, K.; Wang, T.; Cheung, Y.L.; Jiang, P. (2011). Privatization and Risk Sharing: Evidence from the Split Share Structure Reform in China. Review of Financial Studies, 24(7), 24992525 .

Liao, L.; Liu, B.; Wang, H. (2014). China's secondary privatization: Perspectives from the Split-Share Structure Reform. Journal of Financial Economics, 113, 500-518.

Lu, F.; Balatbat, M.C.A.; Czernkowski, R. (2008). The reform of the split share structure in China and its effects on the capital market: an empirical study. Working Paper.

Martin, S., and Parker, D. (1995). "Privatization and economic performance throughout the UK business cycle." Managerial and Decision Economics, 16, 225-237.

McConnell, J.J. and Servaes, H. (1990), "Additional evidence on equity ownership and corporate value," Journal of Financial Economics, 27 (2), 595-612.

Megginson, W.L. and Netter, J.M. (2001). "From state to market: a survey of empirical studies on privatization.” Journal of Economic Literature, 39, 321-389.

Morck, R., Shleifer, A. and Vishny, R.W. (1989), "Alternative Mechanisms for Corporate Control,” Journal of Financial Economics, 79 (4), 842-852.

Myers, S.C. (1977). "Determinants of corporate borrowing." Journal of Financial Economics, $5,147-175$.

Perotti, E.C. (1995). “Credible Privatization.” American Economic Review, 85 (4), 847859. 
Petersen, M. A. (2009). "Estimating standard errors in finance panel data sets: Comparing approaches.” Review of Financial Studies, 22, 435-480.

Sappington, D.E.M. and Stiglitz, J.E. (1987). "Privatization, Information and Incentives”, Journal of Policy Analysis and Management, 6 (4), 567-582.

Schmitz, P.W. (2000), "Partial Privatization and Incomplete Contracts: The Proper Scope of Government Reconsidered”, Finanz Archiv, 57 (4), 394-411.

Shleifer, A. (1998). "State versus Private Ownership", Journal of Economic Perspective, $12(4), 133-150$.

Shleifer, A. and Vishny, R.W. (1994). "Politicians and Firms", Quarterly Journal of Economics, 109 (4), 995-1025.

Shleifer, A. and Vishny, R.W. (1997), "A Survey of Corporate Governance,” Journal of Finance, 52 (2), 737-783.

Sun, Q. and Tong, W.H.S. (2003). "China share issue privatization: the extent of its success.” Journal of Financial Economics, 70, 183-222.

Titman, S. and Wessels, R. (1988), “The Determinants of Capital Structure Choice,” Journal of Finance, 43 (1), 1-19.

Turhan, A. (2005). "Does the Nature of Ownership Matter? Lessons from Theory and Evidence.” Kocaeli Üniversitesi Sosyal Bilimler Enstitüsü Dergisi, 10 (2), 1-20.

Vernon-Wortzel, H. and Wortzel, L.H., (1989). "Privatization: not the only answer." World Development, 17 (5), 633-641.

Vickers, J. and Yarrow, G. (1988). Privatization: An Economic Analysis. MIT Press.

Yermack, D. (1996), "Higher Market Valuation of Companies with a Small Board of Directors," Journal of Financial Economics, 40, 185-211. 